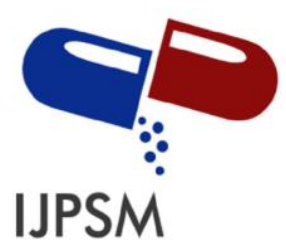

Michael Olabode Tomori et al, Int. Journal of Pharmaceutical Sciences and Medicine (IJPSM),

Vol.6 Issue. 9, September- 2021, pg. 34-78

ISSN: 2519-9889

Impact Factor: 3.426

\title{
EVALUATION OF THE EFFECT OF CORONAVIRUS PANDEMIC ON SUPPLY CHAIN OF HIV TEST KITS ONDO STATE, SOUTHWEST NIGERIA
}

\author{
Michael Olabode Tomori \\ BPharm, MSc, MPH, PhD, MBA \\ Strategic Information Lead, APIN Public Health Initiatives, Akure, Ondo Region/Project Supervisor \& \\ Facilitator National Open University, Akure, Ondo State, Nigeria \\ E-mail address: mtomori@yahoo.com
}

Funmilayo Adenike Fadiji

B.Tech Statistics, MSc Mathematical Sciences

Federal University of Technology, Akure, Ondo State, Nigeria

E-mail address: oluwafunmilayoadenike50@gmail.com

DOI: 10.47760/ijpsm.2021.v06i09.005

\begin{abstract}
COVID-19 pandemic has required swift revamping of health systems and public health measures at a scale never observed. The pandemic emergence has a direct effect on the health system, negatively affecting its capacity as depletion of resources are now channelled to curb the emergency of the communicable disease, especially among individuals living with HIV disease which drew our attention to how individuals suffering from HIV and people who needed to know their HIV status has not been able to visit the health facilities due to the effect of coronavirus pandemic on the supply of the test kits used in the health facilities. This study evaluated the effect of the coronavirus pandemic on the supply chain of HIV test kits in Ondo State, Nigeria. The primary objective was to determine the effect of the coronavirus pandemic on the supply of HIV test kits in Ondo State. The research was a sequential cross-sectional design using a quantitative method of analysis with a total sample size of 100 respondents with all samples drawn from 30 supported health facilities in the state. In addition, literature review was also used to know the effect of the coronavirus on reach of $95 \%$ of UNAIDS 2030 target. The study used both descriptive and inferential methods of data analysis where the descriptive statistics comprise of frequency distribution, percentage distribution, weighted mean score, and standard deviation while the inferential method of data analysis used ordinal least square (simple linear regression) to determine the effect of coronavirus pandemic on the supply chain test kits. Findings from the result concluded that pandemic and the methods of supply chain management indicated a significant effect. In addition, from the review the major impacts of COVID-19 were innovation, increased technology, research and development, depletion of supply chain personnel. Therefore, there is a need to develop national guidelines on supply chain strategy for emergencies in Nigeria as well as adhere strictly to some recommendations made in the study.
\end{abstract}

Keywords: Evaluate, Coronavirus, Supply Chain, HIV test kits, Ondo State 


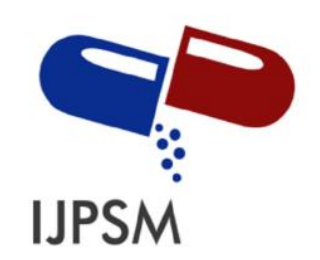

Michael Olabode Tomori et al, Int. Journal of Pharmaceutical Sciences and Medicine (IJPSM), Vol.6 Issue. 9, September- 2021, pg. 34-78

ISSN: 2519-9889

Impact Factor: 3.426

\section{Introduction}

The emergence of pneumonia of an unknown cause in Wuhan China was reported in December 2019. The etiology of this pneumonia was ascribed to a virus of the coronavirus family on the $7^{\text {th }}$ January 2020 and the disease was later named coronavirus disease (COVID19) by the World Health Organization (WHO) on 11 February 2020 (Zhou et al., 2020; Rothan \& Byrareddy, 2020). After an average incubation period of 5.2 days, the COVID-19 symptoms appear on while the median period from the onset of the disease to death is 14 days (WHO, 2020; Rothan \& Byrareddy, 2020). The coronavirus can be transmitted from human to human through direct contact or air droplets from infected persons through coughing or sneezing. Surfaces can also be contaminated by the infection droplets and the virus can remain infectious for several days in the environment that can serve as a reservoir for the infection (Lai et al., 2020). However, most of the infections go into remission without intervention while others will require either hospitalization or intensive care (WHO, 2020).

The complete spread of COVID-19 creates pressure on the health systems and resources that could be utilized for other health conditions are diverted towards the infection. The health system in Sub-Saharan Africa is already weary and is characterized by poor health outcomes with high mortality rates due to the burden of HIV, tuberculosis, and non-communicable diseases and out-of-pocket healthcare.

To curb the COVID-19 epidemic, China imposed restrictions such as lockdown (quarantine) of the whole of Wuhan. Because of the success of this model, some Sub-Saharan Africa countries adopted and implemented the same model. The quarantine measures though are in no way aimed at ending the pandemic but it aims to protect the health systems of the countries from being engulfed by the large number of infected and sick patients who require medical care. This restriction, however, resulted in unintended consequences such as mental health problems, widening inequalities, and worsening poor medical outcomes that are not related to COVID-19. In addition, the Joint United Nations Programme on HIV and AIDS (UNAIDS) and the World Health Organization (WHO) have announced that the number of 


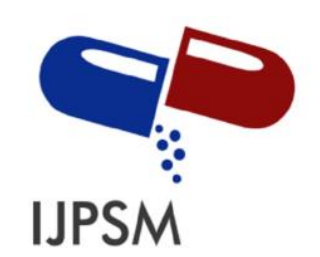

Michael Olabode Tomori et al, Int. Journal of Pharmaceutical Sciences and Medicine (IJPSM), Vol.6 Issue. 9, September- 2021, pg. 34-78

AIDS-related deaths in Sub-Saharan Africa could double if access to healthcare for people living with HIV (PLWHIV) is interrupted during the COVID-19 pandemic. Although interruption to the availability of ARV drugs would have by far the substantial impact of any potential disruptions, suspension of HIV testing would even have the biggest impact on the population (Britta et al., 2020).

Sub-Saharan Africa (SSA) will account for most of the world's population growth in the coming decades as a result of this, the region has persisted as the epicentre of the HIV epidemic (United Nations, 2019; de Mendoza, 2019, p.170-171). However, given the HIV disease burden in Sub-Saharan Africa, the region must continue implementing control efforts during the COVID-19 pandemic (Dzobo et al., 2020). It is very critical to note that the COVID-19 pandemic and associated restrictive measures to curb its spread have stifled HIV testing. The emergence of the COVID-19 pandemic has a direct impact on the health system negatively affecting its functionality especially the availability of supplies such as HIV test kits, health workforce, services suspension, reduced health-seeking behavior, etc (Britta et al., 2020). In an emergency case like coronavirus, the ability to deliver essential services is dependent on the baseline capacity of the health system of which supply chain of HIV test kits are very critical to attaining $95 \%$ of people living with HIV knowing their HIV status which is the first $95 \%$ of the UNAIDS goal to end AIDS by 2030 .

The aim of the study is to evaluate the effect of the coronavirus pandemic on the supply chain of HIV test kits in Ondo State southwest Nigeria.

The objectives are:

1. To assess the effect of coronavirus on the supply chain of HIV test kits.

2. To assess the effect of coronavirus on healthcare workers in charge of HIV test kits.

3. To assess the effect of coronavirus on clients accessing HIV testing.

4. To assess effect of coronavirus on effort to reach the first $95 \%$ UNAIDS target. 


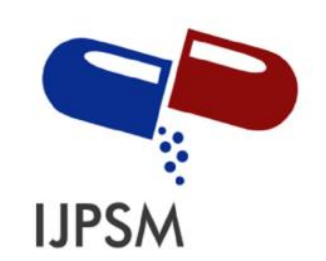

Michael Olabode Tomori et al, Int. Journal of Pharmaceutical Sciences and Medicine (IJPSM), Vol.6 Issue. 9, September- 2021, pg. 34-78

ISSN: 2519-9889

Impact Factor: 3.426

\section{Methods}

\subsection{Research Design}

This study adopted a cross-sectional survey that was descriptive in nature and systematic literature review. The descriptive design was employed because the problems of the research were clearly defined, stated and the researcher aimed to describe the phenomenon. Also, the quantitative research design was adopted in gathering the dataset used for the analysis.

\subsection{Study Area}

Ondo State is located within Lat. $6^{\circ} 43^{1} \mathrm{~N}$ and $7^{\circ} 30^{1} \mathrm{~N}$, and Long. $5^{\circ} 18^{1} \mathrm{E}$ and $6^{\circ} 04^{1} \mathrm{E}$ in the south-western geopolitical zone of Nigeria, created on 3rd February 1976. The state comprised of eighteen (18) local government areas with it headquarter located in Akure South. The population of Ondo State according to the National Population Commission (NPC, 2006) was 3,460,877. The state also has about 576 primary health care centers (OSPHCDB, 2018) with many privates and government hospitals located in all the eighteen (18) local governments. Figure 1 shows the map of the state and the places where the state is sharing boundary with. The boundary states are showing to help get information about how the HIV test kits are supplied and how the boundary states might have an effect in terms of transportation.

\subsection{Study Population}

The study was conducted among the staff of the 30 health facilities supported by the APIN Public Health Initiatives the major implementing partner of US CDC Nigeria in Ondo State South West Nigeria. 


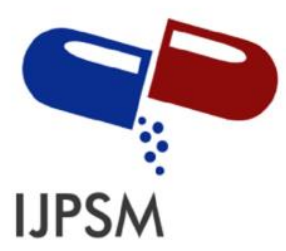

Michael Olabode Tomori et al, Int. Journal of Pharmaceutical Sciences and Medicine (IJPSM), Vol.6 Issue. 9, September- 2021, pg. 34-78

ISSN: 2519-9889

Impact Factor: 3.426

\subsection{Sample Size Determination}

The sample size used for the study was determined using the formula by Taro Yamini (1978) because the population of the study is finite:

$$
\mathrm{n}=\frac{N}{1+N\left(e^{2}\right)}
$$

Where;

$\mathrm{n}=$ sample size;

$\mathrm{N}=$ total population size;

$\mathrm{e}=$ margin of error, and

$1=$ constant

In this research,

$\mathrm{n}=$ ?

$\mathrm{N}=117$

$\mathrm{e}=0.05(5 \%$ margin of error $)$

Substituting into the formula:

$$
\begin{gathered}
\mathrm{n}=\frac{117}{1+117\left(0.05^{2}\right)} \\
\mathrm{n}=\frac{117}{1.2925} \\
\mathrm{n}=90.522 \approx 91 .
\end{gathered}
$$




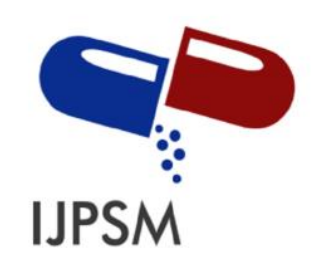

Michael Olabode Tomori et al, Int. Journal of Pharmaceutical Sciences and Medicine (IJPSM), Vol.6 Issue. 9, September- 2021, pg. 34-78

ISSN: 2519-9889

Impact Factor: 3.426

Meanwhile, $10 \%$ of the 91 respondents were added to the sample size, which implies that 91 +9 copies of questionnaires were distributed among the health workers who are involved in the supply of HIV test kits, distribution of HIV tests, and the testing of HIV patients.

Therefore, the total sample size $(n)=100$.

\subsection{Sampling Technique}

This study employed a purposive sampling technique. Denscombe, (2007) explained the purposive sampling technique as the involvement of the selection of a sample of a person with a purpose in their mind which reflect in their qualities and their events, and the relevance of the topic is investigated through them.

\subsection{Study Instrument}

The primary data involved the use of online questionnaires distribution among the laboratory's scientists and technologists in the thirty (30) health facilities supported by CDC through APIN Public Health Initiatives. The study adopted a structured type of questionnaire to carry out the main aim of the study and eliminate the difficulty in dealing with the respondents. The questions were written in English for easy and simple understanding of the respondents. The questionnaire consists of two sections (Section A and B). Section A described the socio-demographic characteristics of the respondents while section B described the variables of the specific objectives itemized in Chapter One. As shown in Appendix 1, the structured questionnaire provided easiness in analyzing the quantitative data.

\subsection{Reliability and Validity of Data}

Reliability testing as explained by Tavakol et al. (2008) determines whether, given the same situation and circumstance, if a test is repeated it will obtain the same result as it did in the first instance, hence the instrument is consistent in its measurement ability. Reliability indicates an error in measurement and a reliable instrument is necessary to give meaning to 


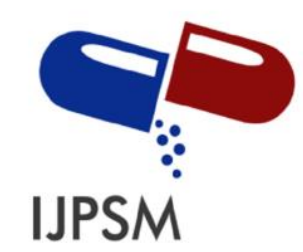

Michael Olabode Tomori et al, Int. Journal of Pharmaceutical Sciences and Medicine (IJPSM), Vol.6 Issue. 9, September- 2021, pg. 34-78

ISSN: 2519-9889

Impact Factor: 3.426

validity; therefore, Duval-Couetil et al. (2011, p.35-36) concluded that reliability and validity are critical, and neither is adequate on its own.

The questionnaires for the investigation were tested and validated by several authors including Liñán and Chen (2009, p.593-617). However, as the current research focused on a different context, the instrument was piloted in June 2021 and further tested for validity and reliability within the research context. The coefficient, Alpha, approximates the average correlation between all pairs of constructs items and the rule applied for interpreting reliability by Cronbach's alpha is as shown in the table below

Table 1: Rules for Reliability Test

\begin{tabular}{cc}
\hline Cronbach's Alpha & Internal Consistency \\
$\alpha \geq 0.9$ & Excellent \\
$0.8 \leq \boldsymbol{\alpha}<0.9$ & Good \\
\hline $0.7 \leq \alpha<0.8$ & Acceptable \\
$\mathbf{0 . 6} \leq \boldsymbol{\alpha}<\mathbf{0 . 7}$ & Questionable \\
\hline $\mathbf{0 . 5} \leq \boldsymbol{\alpha}<\mathbf{0 . 6}$ & Poor \\
\hline $\boldsymbol{\alpha}<\mathbf{0 . 5}$ & Unacceptable \\
\hline
\end{tabular}

\section{Source: Cronbach's Alpha}

The Cronbach's $\alpha$ results range between 0 and 1 and the acceptable reliability score is 0.6 and higher (Tabachnick and Fidell, 2001; Heale and Twycross, 2015). Cronbach's Alpha $>0.7$ is considered as reliable (Nunnally, 1978). A reliability score of less than 0.50 is considered poor because it makes the reliability of the instrument questionable; however, $\alpha$ between 0.60 -0.79 is acceptable; consequently, an $\alpha>0.80$ is considered excellent when it is $>0.90$ (Hair, et al., 1998). Alpha was measured on the same scale as the Pearson's product-moment correlation coefficient which typically varies between 0 and 1 , where the closer the alpha is to 1 the greater the internal consistency of items in the research instrument. 


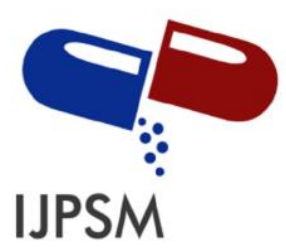

Michael Olabode Tomori et al, Int. Journal of Pharmaceutical Sciences and Medicine (IJPSM), Vol.6 Issue. 9, September- 2021, pg. 34-78

ISSN: 2519-9889

Impact Factor: 3.426

Table 2: Cronbach's Alpha Result

\begin{tabular}{ccc}
\hline Variables & Alpha & Remarks \\
\hline Procurement & 0.932 & Excellent \\
\hline Transportation & 0.911 & Excellent \\
\hline Forecasting and Quantification & 0.762 & Good \\
\hline Healthcare workers in charge & 0.906 & Excellent \\
\hline Clients Accessing & 0.737 & Good \\
\hline Inventory Management & 0.918 & Excellent \\
\hline
\end{tabular}

Source: Researcher's Compilation, 2021.

Given the result in the table above, the Cronbach's alpha of 0.921 was an indication that the instrument was reliable, and consequently, as far as internal consistency is concerned, the instrument has excellent reliability.

\subsection{Data Collection}

After assessing the research aim and objectives, research questions, and hypotheses, the primary source of data collection was used to gather information from the respondents. The primary data was collected through administering online questionnaires among the target respondents in the 30 health facilities supported by APIN in Ondo State, Southwest, Nigeria. The targeted respondents considered are the laboratories scientists, laboratories technologists, Microbiologists, and the focal people. The main reason why the questionnaire is used is that the questionnaire translated the research objectives into specific questions which the respondents are asked to answer. Also, the questionnaire will accelerate the process of data 


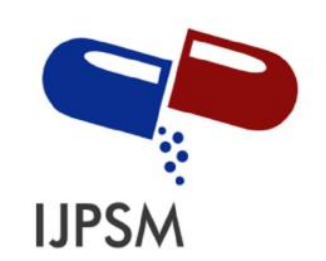

Michael Olabode Tomori et al, Int. Journal of Pharmaceutical Sciences and Medicine (IJPSM), Vol.6 Issue. 9, September- 2021, pg. 34-78

ISSN: 2519-9889

Impact Factor: 3.426

analysis as all the respondents in the 30 health facilities will be asked the same questions and information will be collected on the socio-demographic characteristics of the respondents.

\subsection{Data Analysis}

The data obtained from the online questionnaires were coded, summarized, and analyzed using SPSS, version 26. The two methods of data analysis were employed and used for analyzing the specific objectives. For hypothesis testing, we made use of regression analysis and correlation analysis to the evaluation of the effect of coronavirus pandemic on the supply chain of HIV test kits in Ondo State, Southwest, Nigeria.

For the effect of coronavirus on efforts to reach the first 95\% of UNAIDS target, systematic review was done by using Purdue libraries online access and e-resources centre 'All Databases' search tool. The search was conducted from $1^{\text {st }}$ to $16^{\text {th }}$ August, 2021 using the PRISMA checklist. 200 records was screened and 18 peer reviewed publications and 3 unpublished papers from across countries were also reviewed.

Literature search was done using keywords like "impact of COVID-19", effects of COVID19", "efforts to reach first 95\% UNAIDS target", "effects on HIV test kits", "impact on HIV test kits" and "public health and supply chain" on databases like PubMed, ProQuest, Web of Science, Google Scholar and Science Direct (Elsevier). Literatures that did not report effect or import of COVID-19 on health supply chain and as well those not reported in English. 


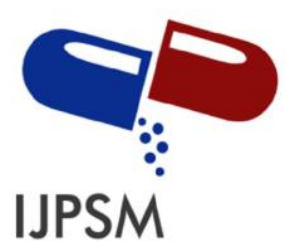

Michael Olabode Tomori et al, Int. Journal of Pharmaceutical Sciences and Medicine (IJPSM), Vol.6 Issue. 9, September- 2021, pg. 34-78

Figure 1 shows the flow chart of this review:

Records identified through database search $n=200$
Additional records identified through other sources $n=3$

\section{Identification}

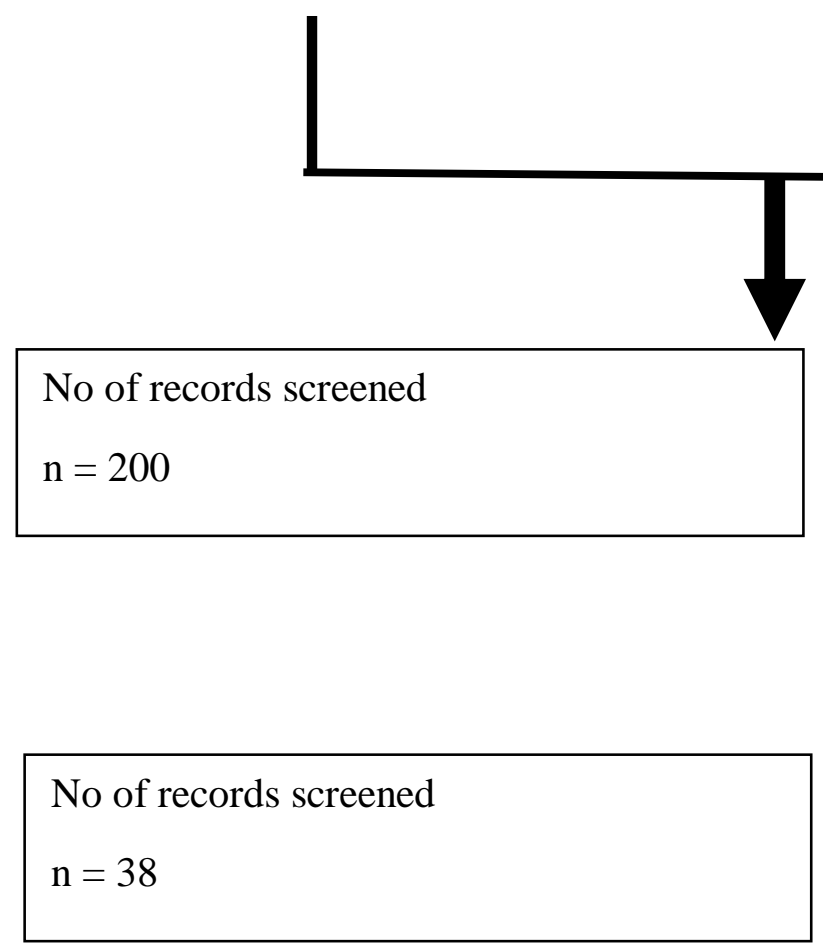

Eligibil
ity

\section{Included}

\section{Screen}

ing

No of records excluded

$\mathrm{n}=162$
Records excluded with reasons

$\mathrm{n}=13$

Studies included in study

$$
\mathrm{n}=25
$$




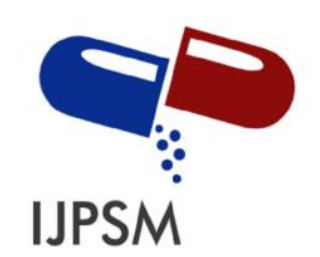

Michael Olabode Tomori et al, Int. Journal of Pharmaceutical Sciences and Medicine (IJPSM), Vol.6 Issue. 9, September- 2021, pg. 34-78

All the 25 studies included in the review were conducted between August and September, 2021. Majority of the studies reviewed were conducted globally (8), in Africa (12), Asia (2) and United States (3). A survey published by the Chartered Institute of Procurement and Supply found that $86 \%$ of supply chains are impacted by the COVID-19 pandemic while another study by the Institute for Supply Management found that between early March and late March, 2020, the number of companies experiencing supply chain impact rose from 80 to 95\% (Van Hoek, 2020).

\subsection{Ethical Approval}

Ethical clearance was conducted in strict compliance with the guidelines specified by the State Ethics Committee. Informed consent was also obtained from each of the respondents with utmost care taken to take care of their privacy and confidentiality.

\section{RESULTS}

One hundred (100) structured questionnaires were distributed online and eighty eight (88) do not contain any missing values and were reported correctly. Therefore, 88 questionnaires were deemed suitable for the analysis.

\subsection{Socio-demographic Characteristics of the Respondents}

This section explains the background information of the respondents at the thirty (30) supported health facilities in Ondo State, Southwest, Nigeria. The background information is analyzed using frequency and percentage distribution. Different variables which investigated the background of the respondents are explained below.

\section{Age of the Respondents}

The age of the respondents is determined using different categories of age groups ranging from less than 18 years to 55 years and above. Table 4.3 is analyzed using frequency and percentage distribution. Meanwhile, $<18$ years is considered in the analysis because of some industrial training/SIWES students who have the experience or are also in the best position to 


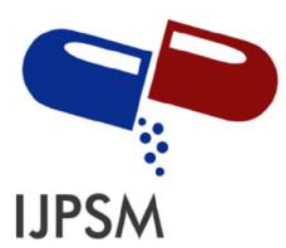

Michael Olabode Tomori et al, Int. Journal of Pharmaceutical Sciences and Medicine (IJPSM), Vol.6 Issue. 9, September- 2021, pg. 34-78

respond to the effect of coronavirus pandemic on the supply chain of HIV test kits among the health workers in Ondo State, Nigeria.

Table 3: Age-group of the Respondents

\begin{tabular}{ccc}
\hline Age & Frequency Distribution & Percentage Distribution \\
\hline < 18 years & 0 & 0.00 \\
\hline $\mathbf{1 8}-\mathbf{2 4}$ years & 4 & 4.50 \\
$\mathbf{2 5}-\mathbf{3 4}$ years & 30 & 34.10 \\
\hline $\mathbf{3 5}-\mathbf{4 4}$ years & 29 & 33.00 \\
\hline $\mathbf{4 5}-\mathbf{5 4}$ years & 25 & 28.40 \\
\hline $\mathbf{5 5}$ years and above & 0 & 0.00 \\
\hline Total & $\mathbf{8 8}$ & $\mathbf{1 0 0 . 0}$ \\
\hline
\end{tabular}

Source: Researcher's Compilation, 2021.

The age group of the respondents is determined using six (6) different categories ranging from $<18$ years to 55 years and above as shown in Table 3 . The result of the analysis shows that the majority of the respondents are between the age of 25 - 30 years with the frequency and percentage of 30 (34.10 percent); followed by 29 (33.00 percent) of the respondents who are between the age of $35-44$ years; 25 (28.40 percent) are between the age of $45-54$ years; 4 (4.50 percent) are between $18-24$ years, no respondent for the age category of $<18$ years and 55 years and above. This proves that the majority of the respondents are between the age of $25-34$ years.

\section{Gender of the Respondents}

This section explains the two forms of gender such as male and female using frequency and percentage distribution to know the number of respondents from either male or female as below: 


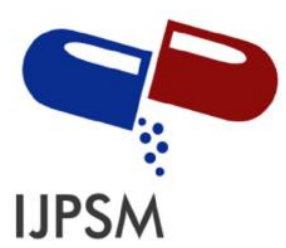

Michael Olabode Tomori et al, Int. Journal of Pharmaceutical Sciences and Medicine (IJPSM), Vol.6 Issue. 9, September- 2021, pg. 34-78

Table 4 Gender of the Respondents

\begin{tabular}{ccc}
\hline Gender & Frequency Distribution & Percentage Distribution \\
\hline Male & 40 & 45.5 \\
\hline Female & 48 & 54.5 \\
\hline Total & $\mathbf{8 8}$ & $\mathbf{1 0 0 . 0}$ \\
\hline
\end{tabular}

Source: Researcher's Compilation, 2021.

From Table 4 above, the result shows that a larger percentage of the respondents are female with the frequency and percentage distribution of 48 (54.5 percent), followed by the male respondents who responded to the effect of coronavirus pandemic on the supply chain and distribution of the HIV test kits. This implies that more female works in the department where HIV test kits are supplied and distributed to. This might be because the female can easily take and advise people, especially their female gender than male. Also, in health workers, more females are found than male.

\section{Marital Status of the Respondents}

The status of the health workers in the 30 health facilities supported by APIN Public Health Initiatives and USAID is analyzed using frequency and percentage distribution. The categories of the marital status considered include single, married, divorced, widowed/widower, and separated.

Table 5: Marital Status of the Respondents

\begin{tabular}{ccc}
\hline Marital Status & Frequency Distribution & Percentage Distribution \\
\hline Single & 22 & 25.00 \\
Married & 66 & 75.00 \\
\hline
\end{tabular}




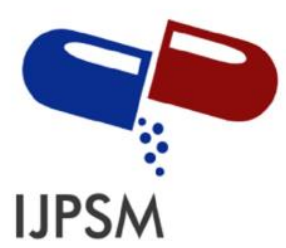

Michael Olabode Tomori et al, Int. Journal of Pharmaceutical Sciences and Medicine (IJPSM), Vol.6 Issue. 9, September- 2021, pg. 34-78

\begin{tabular}{|ccc|}
\hline Separated & 0 & 0.00 \\
\hline Divorced & 0 & 0.00 \\
\hline Widowed/widower & 0 & 0.00 \\
\hline Total & $\mathbf{8 8}$ & $\mathbf{1 0 0 . 0 0}$ \\
\hline
\end{tabular}

\section{Source: Researcher's Compilation, 2021.}

It is observed that a larger percentage of the respondents are married with the frequency and percentage distribution of 66 (75.0 percent) while 22 (25.0 percent) are of the health workers involved in filling the questionnaire are single and no respondents for separated, widowed/widower, and divorced. This implies that the respondents who are involved in the supply chain and the distribution of the HIV test kits are married.

\section{Highest Educational Level}

The educational level of the health workers is of different categories. The level of education includes primary, secondary, NCE, HND, BSc, BLMS, Masters, Ph.D., and others using frequency and percentage distribution. This is to indicate whether the health workers involved in the supply and distribution of the HIV test kits are educated or not. The result of the analysis is explained in Table 4.5 .

Table 4.5: Educational level of the Respondents

\begin{tabular}{|ccc|}
\hline Educational Level & Frequency Distribution & Percentage Distribution \\
\hline Primary/Secondary School & 0 & 0.00 \\
\hline NCE/OND & 14 & 15.90 \\
\hline HND/BSc/B.Tech/BMLS & 38 & 43.20 \\
\hline MSc/M.Tech/M.Phil & 32 & 15.90 \\
\hline PhD & 0 & 0.00 \\
\hline Others & 4 & 4.50 \\
\hline Total & $\mathbf{8 8}$ & $\mathbf{1 0 0 . 0 0}$ \\
\hline
\end{tabular}

Source: Researcher's Compilation, 2021 


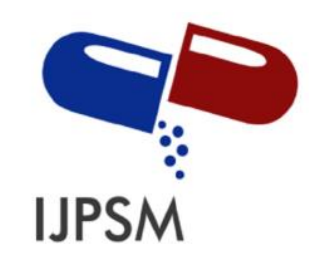

Michael Olabode Tomori et al, Int. Journal of Pharmaceutical Sciences and Medicine (IJPSM), Vol.6 Issue. 9, September- 2021, pg. 34-78

ISSN: 2519-9889

Impact Factor: 3.426

\section{Department of the Respondents}

The department who are more likely to be involved in the supply chain and distribution of the HIV test kits as well as testing the HIV patients include the laboratories scientist, PMTCT focal person, laboratories technologist, microbiologists, and others were considered to determine whether the other people might be involved in the distribution and the supply of the HIV test kits among the health workers through the support of CDC through APIN Public Health Initiatives and USAID.

Table 7: Department of the Respondents

\begin{tabular}{ccc}
\hline Department & Frequency Distribution & Percentage Distribution \\
\hline Laboratories Scientist & 58 & 65.90 \\
\hline PMTCT focal person & 0 & 0.00 \\
\hline Laboratories Technologist & 22 & 25.10 \\
\hline Microbiologists & 4 & 4.50 \\
\hline Others & 4 & 4.50 \\
\hline Total & $\mathbf{8 8}$ & $\mathbf{1 0 0 . 0 0}$ \\
\hline
\end{tabular}

\section{Source: Researcher's Compilation, 2021.}

Table 7 shows that 58 (65.90 percent) of the respondents are laboratories scientists; followed by 22 ( 25.10 percent) who are laboratories technologist; 4 (4.50 percent) are microbiologists and others while there are no respondents for PMTCT focal persons. This shows that the majority of the respondents are laboratories scientists.

\section{Years of Experience}

The experience of the respondents is determined using years. The years include $<5$ years; $6-$ 10 years; 11 - 15 years, and 16 years and above. This is analyzed using frequency and percentage distribution as explained in Table 8. 


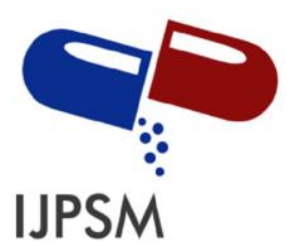

Michael Olabode Tomori et al, Int. Journal of Pharmaceutical Sciences and Medicine (IJPSM), Vol.6 Issue. 9, September- 2021, pg. 34-78

Table 8: Years of Experience of the Respondents

\begin{tabular}{ccc}
\hline Years of Experience & Frequency Distribution & Percentage Distribution \\
\hline $\mathbf{0}-\mathbf{5}$ years & 18 & 20.50 \\
\hline $\mathbf{6}-\mathbf{1 0}$ years & 34 & 38.60 \\
$\mathbf{1 1}-\mathbf{1 5}$ years & 10 & 11.40 \\
\hline $\mathbf{1 6}$ years and above & 26 & 29.50 \\
\hline Total & $\mathbf{8 8}$ & $\mathbf{1 0 0 . 0 0}$ \\
\hline
\end{tabular}

\section{Source: Researcher's Compilation, 2021.}

34 (38.60 percent) of the respondents have about $6-10$ years of working experience; followed by the health workers who have 16 years and above working experience with the frequency and percentage distribution of 26 (29.50 percent); 18 (20.50 percent) have < 5 years of working experience, and 10 (11.40 percent) have 11 - 15 years of working experience. This proves that the majority of the respondents have $6-10$ years of working experience as well as the health workers are having one experience or the other.

\section{Regular Supply of HIV Test Kits}

A question was asked on "are HIV test kits regularly supply to your health facilities?" using frequency and percentage distribution. The respondent was asked to respond to "Yes" or "No".

Table 9: Regular Supply of HIV Test Kits

\begin{tabular}{ccc}
\hline Variable & Frequency Distribution & Percentage Distribution \\
\hline Yes & 88 & 100.00 \\
No & 0 & 0.00 \\
\hline Total & $\mathbf{8 8}$ & $\mathbf{1 0 0 . 0}$ \\
\hline
\end{tabular}

Source: Researcher's Compilation, 2021. 


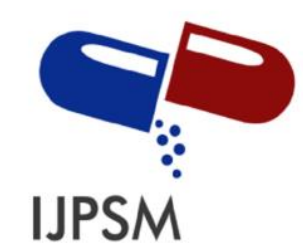

Michael Olabode Tomori et al, Int. Journal of Pharmaceutical Sciences and Medicine (IJPSM), Vol.6 Issue. 9, September- 2021, pg. 34-78

ISSN: 2519-9889

Impact Factor: 3.426

The response shows that in the 30 health facilities, there is a regular supply of health facilities with a frequency and percentage distribution of 88 (100.0). This has proved that the selected 30 health facilities regularly supply the HIV test kits even during the coronavirus pandemic.

\section{Often Testing Patients for HIV}

The health workers were asked whether the patients are often tested for HIV as shown in the Table below. The result is analyzed using frequency and percentage distribution.

Table 10: Often Testing Patients for HIV

\begin{tabular}{ccc}
\hline Variable & Frequency Distribution & Percentage Distribution \\
\hline Always & 84 & 95.50 \\
Once a week & 0 & 0.00 \\
\hline Once in a while & 4 & 4.50 \\
Total & $\mathbf{8 8}$ & $\mathbf{1 0 0 . 0}$ \\
\hline
\end{tabular}

\section{Source: Researcher's Compilation, 2021.}

The health facilities always test patients for HIV with the highest frequency and percentage distribution of 84 (95.50 percent) while 4 (4.50 percent) of the health facilities test their patients once in a while with no respondents for once in a week. This shows that a larger percentage of the respondents always test their patients for HIV.

\section{Supply HIV Test Kits}

Supplying HIV test kits are determined using always, once in a week, and once in a while, analyzed using frequency and percentage distribution. The health workers responded accordingly. 


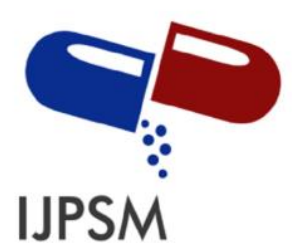

Michael Olabode Tomori et al, Int. Journal of Pharmaceutical Sciences and Medicine (IJPSM), Vol.6 Issue. 9, September- 2021, pg. 34-78

Table 11: Supply HIV Test Kits

\begin{tabular}{ccc}
\hline Variable & Frequency Distribution & Percentage Distribution \\
\hline Always & 76 & 86.40 \\
Once a week & 2 & 2.20 \\
\hline Once in a while & 10 & 11.40 \\
\hline Total & $\mathbf{8 8}$ & $\mathbf{1 0 0 . 0}$ \\
\hline
\end{tabular}

Source: Researcher's Compilation, 2021.

As shown in Table 11, the health facilities are always supplied HIV test kits with the frequency and percentage distribution of 76 (86.40 percent) while 10 (11.40 percent) of the health workers do supply HIV test kits once in a while, and 2 (2.20 percent) of the health facilities supply test kits once in a week. This shows that the majority of the health facilities are always supplied HIV test kits by CDC through APIN Public Health and USAID even during the coronavirus pandemic.

\section{Enough HIV Test Kits}

This discusses whether the health facilities are being supplied with enough HIV test kits with the frequency and percentage distribution as explained in the Table below. The result is shown as a result of either yes or no response from the respondents of the health facilities.

Table 12: Enough HIV Test Kit

\begin{tabular}{ccc}
\hline Variable & Frequency Distribution & Percentage Distribution \\
\hline Yes & 86 & 97.70 \\
No & 2 & 2.30 \\
Total & $\mathbf{8 8}$ & $\mathbf{1 0 0 . 0}$ \\
\hline
\end{tabular}

\section{Source: Researcher's Compilation, 2021.}

As indicated in the Table above, the result shows that 86 (97.70 percent) of the respondents responded that the health facilities are always supplied with enough HIV test kits while only 2 respondents said their health facilities are not supplied with enough HIV test kits. 


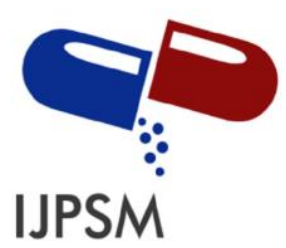

Michael Olabode Tomori et al, Int. Journal of Pharmaceutical Sciences and Medicine (IJPSM), Vol.6 Issue. 9, September- 2021, pg. 34-78

ISSN: 2519-9889

Impact Factor: 3.426

\subsection{Effect of Coronavirus pandemic on the supply chain of HIV test kits}

In this section, the effect of the coronavirus pandemic on the supply chain of HIV test kits was analyzed using frequency and percentage distribution, weighted mean score, standard deviation, and ranking. The analysis is conducted on each of the variables used in each objective. The analysis is shown in the table below.

In this section, the effect of the coronavirus pandemic on the supply chain of HIV test kits was analyzed using frequency and percentage distribution, weighted mean score, standard deviation, and ranking. The analysis is conducted on each of the variables used in each objective. The analysis is shown in the table below.

Table 13: Effect of Coronavirus Pandemic on Supply Chain of HIV Test Kits

\begin{tabular}{|c|c|c|c|c|c|c|c|}
\hline \multirow[b]{2}{*}{ Variables } & \multicolumn{5}{|c|}{$\begin{array}{c}\text { Frequency and Percentage } \\
\text { Distribution }\end{array}$} & \multicolumn{2}{|c|}{$\begin{array}{c}\text { Weighted Mean } \\
\text { Score }\end{array}$} \\
\hline & $\begin{array}{l}\text { SD } \\
(\%)\end{array}$ & $\begin{array}{c}\text { D } \\
(\%)\end{array}$ & $\begin{array}{c}\mathrm{N} \\
(\%)\end{array}$ & $\begin{array}{c}\mathrm{A} \\
(\%)\end{array}$ & $\begin{array}{l}\text { SA } \\
(\%)\end{array}$ & Statistic & Rank \\
\hline $\begin{array}{c}\text { Effect of Coronavirus } \\
\text { Pandemic }\end{array}$ & & & & & & & \\
\hline $\begin{array}{l}\text { Coronavirus has affected the } \\
\text { population of people and } \\
\text { staff visiting the health } \\
\text { facilities }\end{array}$ & $\begin{array}{c}14 \\
(15.9)\end{array}$ & $\begin{array}{c}14 \\
(15.9)\end{array}$ & $\begin{array}{c}8 \\
(9.1)\end{array}$ & $\begin{array}{c}18 \\
(20.5)\end{array}$ & $\begin{array}{c}34 \\
(38.6)\end{array}$ & 3.50 & 1 \\
\hline $\begin{array}{l}\text { COVID-19 has affected the } \\
\text { timing and location of the } \\
\text { health facilities. }\end{array}$ & $\begin{array}{c}30 \\
(34.1)\end{array}$ & $\begin{array}{c}18 \\
(20.5)\end{array}$ & $\begin{array}{c}8 \\
(9.1)\end{array}$ & $\begin{array}{c}8 \\
(9.1)\end{array}$ & $\begin{array}{c}24 \\
(27.3)\end{array}$ & 2.75 & 2 \\
\hline Procurement of HIV test kits & & & & & & & \\
\hline
\end{tabular}




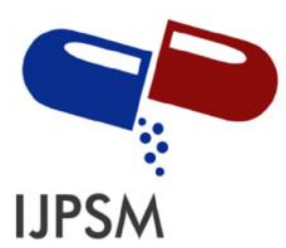

Michael Olabode Tomori et al, Int. Journal of Pharmaceutical Sciences and Medicine (IJPSM), Vol.6 Issue. 9, September- 2021, pg. 34-78

ISSN: 2519-9889

Impact Factor: 3.426

\begin{tabular}{|c|c|c|c|c|c|c|c|}
\hline $\begin{array}{l}\text { There are challenges in the } \\
\text { distribution of HIV test kits } \\
\text { at the peak of COVID-19 }\end{array}$ & $\begin{array}{c}46 \\
(52.3)\end{array}$ & $\begin{array}{c}26 \\
(29.5)\end{array}$ & $\begin{array}{c}6 \\
(6.8)\end{array}$ & $\begin{array}{c}8 \\
(9.1)\end{array}$ & $\begin{array}{c}2 \\
(2.3)\end{array}$ & 1.80 & 2 \\
\hline $\begin{array}{l}\text { There are difficulties in the } \\
\text { collection of HIV test kits at } \\
\text { the peak of COVID-19 }\end{array}$ & $\begin{array}{c}52 \\
(59.1)\end{array}$ & $\begin{array}{c}22 \\
(25.0)\end{array}$ & $\begin{array}{c}4 \\
(4.5)\end{array}$ & $\begin{array}{c}6 \\
(6.8)\end{array}$ & $\begin{array}{c}4 \\
(4.5)\end{array}$ & 1.73 & 3 \\
\hline $\begin{array}{l}\text { There are inadequate health } \\
\text { workers for the collection of } \\
\text { HIV test kits }\end{array}$ & $\begin{array}{c}28 \\
(31.8)\end{array}$ & $\begin{array}{c}22 \\
(25.0)\end{array}$ & $\begin{array}{c}8 \\
(9.1)\end{array}$ & $\begin{array}{c}10 \\
(11.4)\end{array}$ & $\begin{array}{c}20 \\
(22.7)\end{array}$ & 2.68 & 1 \\
\hline
\end{tabular}

\section{Transportation/Distribution}

of the HIV test kits

Inadequate use of

$48 \quad 20$

$20 \quad 4$

$4 \quad 8 \quad 8$

transportation

$(54.5) \quad(22.7) \quad(4.5)$

$(9.1)$

(9.1) $\quad 1.95$

2

It is difficult to reach our

health facilities since it is one $\quad \begin{array}{llllll}60 & 12 & 12 & 0 & 4\end{array}$

$\begin{array}{llllllll}\text { of the hard to reach health } & (68.2) & (13.6) & (13.6) & (0.0) & (4.5) & 1.59 & 4\end{array}$

facilities

Bad roads are one of the $\quad \begin{array}{llllll}56 & 12 & 8 & 0 & 12\end{array}$

$\begin{array}{llllllll}\text { major factors the health } & (63.6) & (13.6) & (9.1) & (0.0) & (13.6) & 1.86 & 3\end{array}$

facility does not supply HIV

test

\section{Coronavirus pandemic}

causes a delay in the

$\begin{array}{ccccccccc}\text { transportation/distribution of } & 46 & 4 & 14 & 16 & 8 & 2.27 & 1 \\ \text { HIV test kits to supported } & (52.3) & (4.5) & (15.9) & (18.2) & (9.1) & & \\ \text { health facilities. } & & & & & & \end{array}$




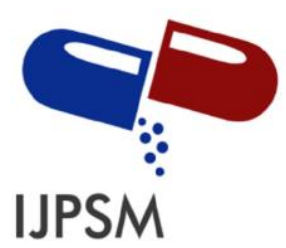

Michael Olabode Tomori et al, Int. Journal of Pharmaceutical Sciences and Medicine (IJPSM), Vol.6 Issue. 9, September- 2021, pg. 34-78

\section{Forecasting and}

\section{Quantification of HIV test}

kits

\begin{tabular}{|cccccccc|}
\hline $\begin{array}{c}\text { Supported health facilities } \\
\text { encounter a shortage of HIV }\end{array}$ & 62 & 14 & 6 & 6 & 0 & & \\
test kits due to coronavirus & $(70.5)$ & $(15.9)$ & $(6.8)$ & $(6.8)$ & $(0.0)$ & 1.50 & 4 \\
\hline $\begin{array}{c}\text { The coronavirus pandemic } \\
\text { deprives some supported } \\
\text { health facilities of getting }\end{array}$ & $(63.6)$ & $(13.6)$ & $(9.1)$ & $(9.1)$ & $(4.5)$ & & \\
HIV test kits & & & & & & & \\
\hline
\end{tabular}

The pandemic causes the

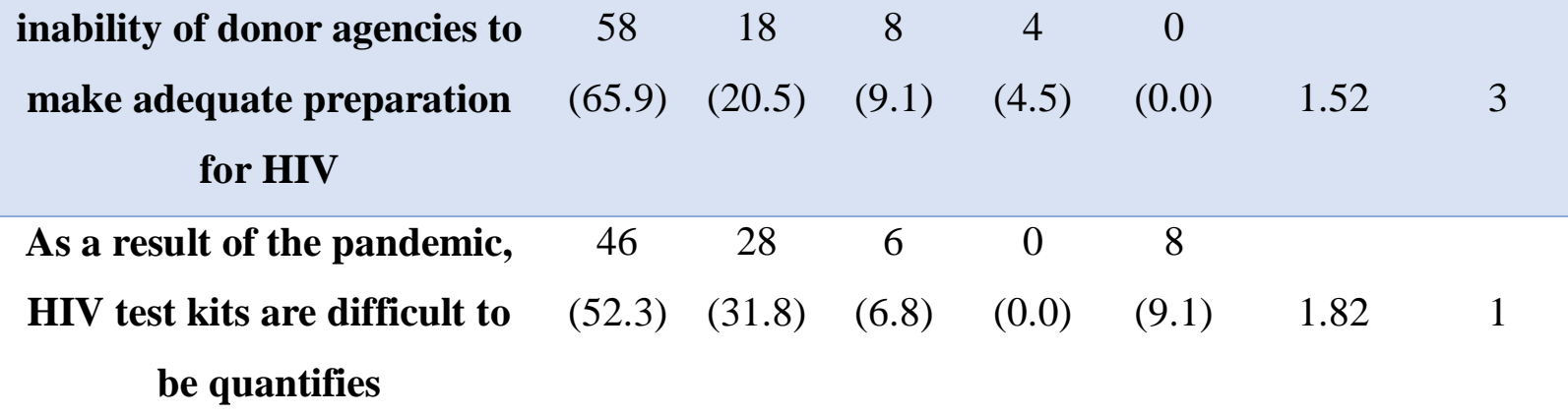

\section{Health workers in charge of \\ HIV test kits}

Health workers in charge of

$\begin{array}{llllll}\text { HIV test kits are } & 32 & 30 & 2 & 10 & 14\end{array}$

$\begin{array}{lllllll}\text { overwhelmed with work as a } & (36.4) & (34.1) & (2.3) & (11.4) & (15.9) & 2.36\end{array}$

result of the pandemic

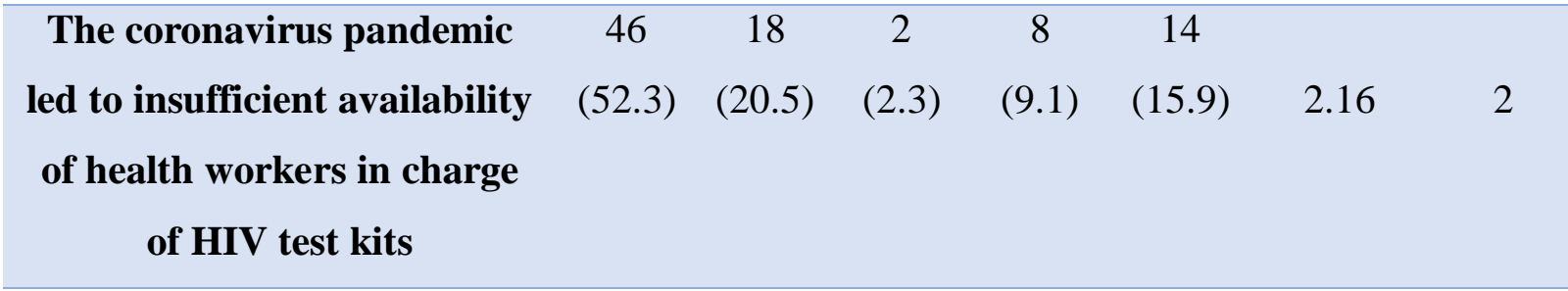




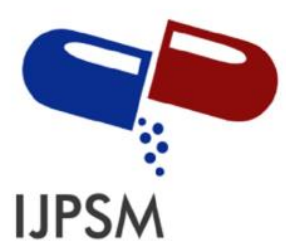

Michael Olabode Tomori et al, Int. Journal of Pharmaceutical Sciences and Medicine (IJPSM), Vol.6 Issue. 9, September- 2021, pg. 34-78

ISSN: 2519-9889

Impact Factor: 3.426

$\begin{array}{cccccccc}\text { Health workers in charge of } & 62 & 16 & 0 & 4 & 6 & & \\ \text { HIV tests have limited test } & (70.5) & (18.2) & (0.0) & (4.5) & (6.8) & 1.59 & 3\end{array}$

kits to work with as a result

of the pandemic

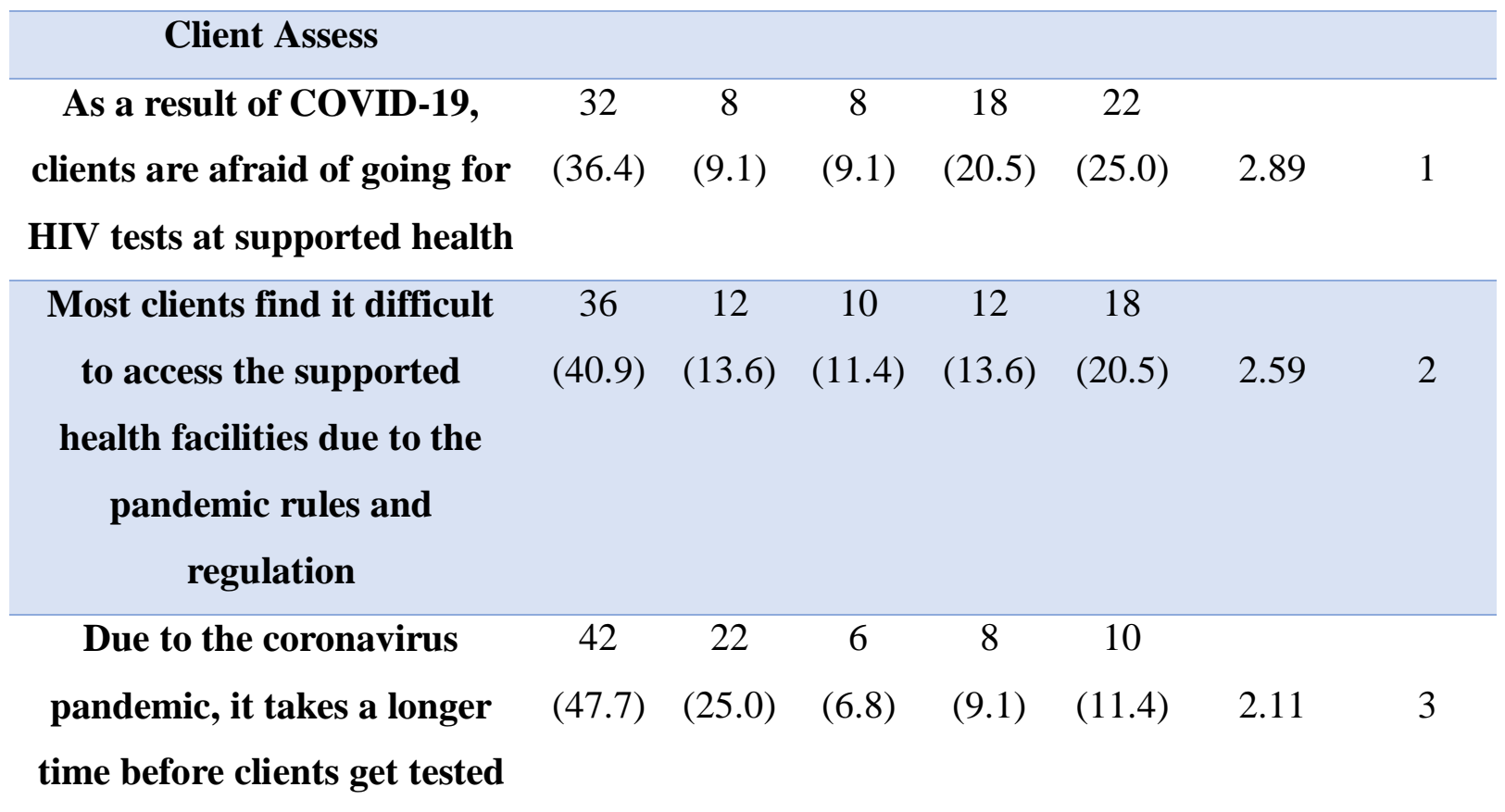

Inventory management of the
HIV test kits

Coronavirus pandemic

makes proper documentation $\quad \begin{array}{llllll}50 & 26 & 8 & 0 & 4\end{array}$

$\begin{array}{llllllll}\text { of HIV test kits difficult } & (56.8) & (29.5) & (9.1) & (0.0) & (4.5) & 1.66 & 2\end{array}$

\section{Accountability of HIV test}

$\begin{array}{llllll}\text { kits is an issue of concern as } & 44 & 30 & 2 & 0 & 12\end{array}$

$\begin{array}{llllllll}\text { a result of the pandemic } & (50.0) & (34.1) & (2.3) & (0.0) & (13.6) & 1.93 & 1\end{array}$

\section{Source: Researcher's Compilation, 2021.}

The weighted mean score is used to determine the factor which mostly has an effect of coronavirus pandemic on the supply chain of the HIV test kits among the health facilities in 


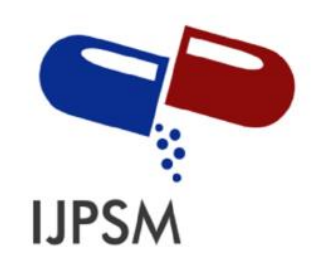

Michael Olabode Tomori et al, Int. Journal of Pharmaceutical Sciences and Medicine (IJPSM), Vol.6 Issue. 9, September- 2021, pg. 34-78

ISSN: 2519-9889

Impact Factor: 3.426

Ondo State, Nigeria using the mode of each of the variables (that is, the highest frequency and percentage distribution) identified by each of the response obtained.

Table 13 shows the variables used to measure the objectives tested in Chapter One above. The variables considered include Procurement of HIV test kits. For the effect of coronavirus pandemic, it is observed that Coronavirus has affected the population of people and staff visiting the health facilities with the weighted mean score of 3.50 being rated "Strongly Agreed" by the mode (highest frequency and percentage distribution) of 34 (38.6 percent) while the other variables show that respondents COVID-19 has affected the timing and location of the health facilities $(2.75 \mathrm{wms})$ being rated "Strongly disagreed" by the mode of 30 (34.1percent). This has proved that coronavirus has affected the population of people and staff visiting the health facilities as well as the time and location of the health facilities.

For procurement of HIV test kits, Inadequate health workers for the collection of HIV test kits (2.68 wms) being rated "Strongly Disagreed" by the mode of 28 (31.8 percent); Challenges in the distribution of HIV test kits at the peak of COVID-19 (1.80 wms) being rated "strongly disagreed" by 46 (52.3 percent), and difficulties in collection of HIV test kits at the peak of COVID-19 being rated "Strongly Disagreed" by 52 (59.1 percent). This explains that there are inadequate health workers for the collection of HIV test kits. Also, there are no challenges in the distribution of HIV test kits at the peak of COVID-19 among the health facilities.

For transportation or the distribution of HIV test kits, coronavirus pandemic causes a delay in the transportation/distribution of HIV test kits to supported health facilities with the weighted mean score of (2.27) being rated by "Strongly Disagreed" by the highest frequency and percentage distribution of 46 (52.3 percent); inadequate use of transportation is another variable considered in the transportation/distribution of HIV test among the health facilities. The result of the analysis shows wms value of 1.95 being rated "Strongly Disagreed" by 48 (54.5 percent); Bad roads are one of the major factors the health facility does not supply HIV test (1.86 wms) being rated "Strongly disagreed" by 56 (63.6 percent), and difficulties to 


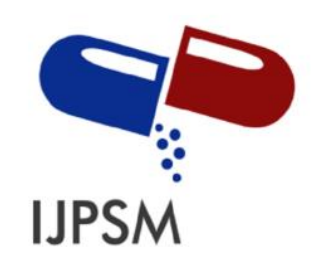

Michael Olabode Tomori et al, Int. Journal of Pharmaceutical Sciences and Medicine (IJPSM), Vol.6 Issue. 9, September- 2021, pg. 34-78

ISSN: 2519-9889

Impact Factor: 3.426

reach our health facilities since it is one of the hard to reach health facilities (1.59 wms) being rated "Strongly disagreed" by 60 ( 68.2 percent $)$. This shows that there is adequate use of transportation, the health facilities are not difficult to reach, bad roads are not the major factors for not supply HIV tests, and coronavirus pandemics do not cause a delay in the transportation/distribution of HIV test kits to supported health facilities.

The result displayed for forecasting and quantification of HIV test kits shows that HIV test kits are not difficult to be quantified with the weighted mean score of (1.82) being rated "Strongly disagreed" by 46 (52.3 percent); followed by coronavirus pandemic deprives some supported health facilities of getting HIV test kits (1.77 wms) being rated "Strongly Disagreed" by the highest frequency and percentage distribution of 56 (63.6 percent); pandemic causes the inability of donor agency to make adequate preparation for HIV (1.52 wms) being rated "Strongly disagreed" by the highest frequency and percentage distribution of 58 (65.6 percentage) and shortage of HIV test kits due to coronavirus (1.50 wms) being rated "Strongly Disagreed" by 62 (70.5 percent). This indicates that there is no shortage of HIV test kits due to coronavirus, coronavirus pandemic does not deprive some supported health facilities, HIV test kits are not difficult to quantify, and there are no causes of the inability of donor agencies to make adequate preparation for HIV test.

Meanwhile, another variable is considered under the effect of coronavirus pandemic on supply chain HIV test kits and the variable is client assessing of the HIV test kits. From the variable, it is deduced that clients are not afraid of going for HIV tests at the supported health facilities. This is as a result of the findings obtained from the table above where we have a wms of (2.89) being rated "Strongly Disagreed" by 32 (36.4); followed by respondents who said Most clients find it difficult to access the supported health facilities due to the pandemic rules and regulation (2.59 wms) being rated "Strongly Disagreed" by 36 (40.9 percent); Health workers in charge of HIV test kits are overwhelmed with work as a result of the pandemic (2.36 wms) being rated "Strongly Disagreed" by 32 (36.4 percent); The coronavirus pandemic led to insufficient availability of health workers in charge of HIV test 


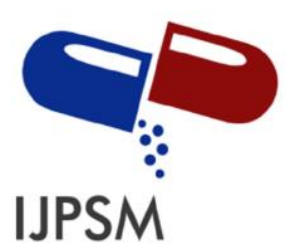

Michael Olabode Tomori et al, Int. Journal of Pharmaceutical Sciences and Medicine (IJPSM), Vol.6 Issue. 9, September- 2021, pg. 34-78

kits (2.16 wms) being rated "Strongly disagreed" by 46 (52.3 percent); Due to the coronavirus pandemic, it takes longer time before clients get tested $(2.11 \mathrm{wms})$ being rated "Strongly disagreed" by 42 (47.7 percent), and Health workers in charge of HIV test have limited test kits to work with as a result of the pandemic (1.59 wms) being rated "Strongly Disagreed" by 62 (70.50 percent). This indicates that the clients must assess the supported health facilities for the testing and regular checking of the HIV status. The result further shows the result of the inventory management of the HIV test kits, the result shows that accountability of HIV test kits is not an issue of concern as a result of the pandemic since it has the highest weighted mean score of 1.93 being rated "Strongly Disagreed" by 44 (50.0 percent) while coronavirus pandemic does not make proper documentation of HIV test kits difficult because the majority of the respondents disagreed with the result showing the wms of 1.66 being rated "Strongly Disagreed.

\subsubsection{Descriptive Statistics of the Respondents}

The summary statistics of the variables used in the objectives are presented in the table below. The result shows the minimum value, maximum value, standard deviation, mean value, and the number of observations considered in each variable displayed in Table below:

Table 14 Descriptive Statistics of the Explanatory Variables

\begin{tabular}{|lccccc|}
\hline & Observation & Minimum & Maximum & Mean & $\begin{array}{c}\text { Std. } \\
\text { Deviation }\end{array}$ \\
\hline Procurement & 88 & 1.33 & 4.67 & 3.44 & 1.21 \\
\hline Transportation & 88 & 1.00 & 4.50 & 3.51 & 1.06 \\
\hline Forecasting & 88 & 1.00 & 4.25 & 3.40 & 1.12 \\
\hline $\begin{array}{l}\text { Health workers } \\
\text { in charge }\end{array}$ & 88 & 1.33 & 4.67 & 3.52 & 1.11 \\
\hline Client Assessing & 88 & 1.00 & 5.00 & 3.56 & 1.39 \\
\hline $\begin{array}{l}\text { Inventory } \\
\text { Management }\end{array}$ & 88 & 1.00 & 4.00 & 2.84 & 1.33 \\
\hline
\end{tabular}

Source: Researcher's Compilation, 2021. 


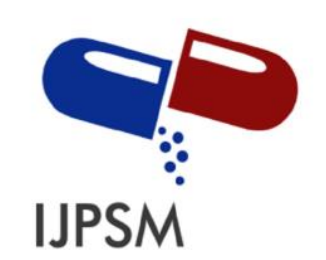

Michael Olabode Tomori et al, Int. Journal of Pharmaceutical Sciences and Medicine (IJPSM), Vol.6 Issue. 9, September- 2021, pg. 34-78

ISSN: 2519-9889

Impact Factor: 3.426

\section{Procurement}

As indicated in Table 14, the procurement has a mean value of (3.44) with a standard deviation of (1.21) showing the minimum value of (1.33) and the maximum value of (4.67). This shows some level of variation in the procurement of HIV test kits among the supported health facilities.

\section{Transportation}

From Table 14, the transportation or distribution of the HIV test kits has a mean value of (3.51) with a standard deviation of (1.06). The minimum and the maximum value of the results show 1.00 and 4.50 respectively which explains the level of the transportation or the distribution of the HIV test kits among the supported health workers in Ondo State, Nigeria.

\section{Forecasting and Quantification}

Considering the effect of the coronavirus pandemic on the supply of HIV test kits among the health facilities, forecasting, and quantification of HIV test kits is an independent variable in this section. The analysis shows that forecasting and quantification of HIV test kits has a mean value of 3.40 and a standard deviation of (1.12) with a minimum value of 1.00 while the maximum value is 4.25 . It is also observed that the total number of observations is given as 88 .

\section{Health workers in charge of HIV test kits}

The effect of coronavirus pandemic on the supply of HIV test kits among the health facilities in Ondo State. Data obtained shows that the mean value is given as (3.52), the standard deviation of (1.11), a minimum value of (1.33), and the maximum value of (4.67). Also, the result reveals that 88 respondents were used in the analysis.

\section{Client Assessing}

Client Assessing is another variable used to determine the effort of the supply chain HIV test kits among the supported health facilities in this research, the result shows the mean value of 


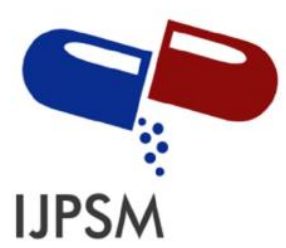

Michael Olabode Tomori et al, Int. Journal of Pharmaceutical Sciences and Medicine (IJPSM), Vol.6 Issue. 9, September- 2021, pg. 34-78

(3.58), a standard deviation of (1.39), a minimum value of (1.00), and maximum value of (5.00). The total observation used in this case is 88 respondents.

\section{Inventory Management}

The last variable considered among the objective is inventory management. This is part of the variable used to determine the effect of the coronavirus pandemic on the supply of HIV test kits in Ondo State. The summary statistics of the variable are also considered. It is shown from Table 4.13 that the mean value is given as (2.84), the standard deviation of (1.33), the minimum value of (1.00), and the maximum value of (4.00). The total number of observations is given as 88 respondents.

\subsubsection{Bivariate Analysis}

In explaining the strength and the level of relationship between each pair of the effect of coronavirus pandemic and the explanatory variable identified in the study and to ensure the correlation among the independent variables are not too high to the extent of having multicollinearity problem, a bivariate analysis is employed and the result is explained as displayed below.

Table 15: Bivariate Analysis

\begin{tabular}{|c|c|c|c|c|c|c|}
\hline & $\begin{array}{c}\text { Effect of } \\
\text { coronavirus } \\
\text { Pandemic }\end{array}$ & Procurement & Transportation & Forecasting & $\begin{array}{c}\text { Client } \\
\text { Assessing }\end{array}$ & $\begin{array}{c}\text { Inventory } \\
\text { Management }\end{array}$ \\
\hline $\begin{array}{c}\text { Effect of } \\
\text { coronavirus } \\
\text { Pandemic }\end{array}$ & 1.000 & & & & & \\
\hline Procurement & $\begin{array}{c}0.688^{* * *} \\
(0.000)\end{array}$ & 1.000 & & & & \\
\hline Transportation & $\begin{array}{c}0.599 * * * \\
(0.000)\end{array}$ & $\begin{array}{c}0.836^{* * * *} \\
(0.000)\end{array}$ & 1.000 & & & \\
\hline Forecasting & $\begin{array}{c}0.630 * * * \\
(0.000)\end{array}$ & $\begin{array}{c}0.887 * * * \\
(0.000)\end{array}$ & $\begin{array}{c}0.890 * * * \\
(0.000)\end{array}$ & 1.000 & & \\
\hline
\end{tabular}




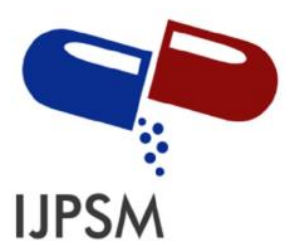

Michael Olabode Tomori et al, Int. Journal of Pharmaceutical Sciences and Medicine (IJPSM), Vol.6 Issue. 9, September- 2021, pg. 34-78

ISSN: 2519-9889

Impact Factor: 3.426

\begin{tabular}{ccccccc} 
Client & $0.579^{* * *}$ & $0.860^{* * *}$ & $0.803^{* * *}$ & $0.766^{* * *}$ & 1.000 & \\
Assessing & $(0.000)$ & $(0.000)$ & $(0.000)$ & $(0.000)$ & & \\
\hline Inventory & $0.583^{* * *}$ & $0.876^{* * *}$ & $0.797 * * *$ & $0.791 * * *$ & $0.878^{* * *}$ & 1.000 \\
Management & $(0.000)$ & $(0.000)$ & $(0.000)$ & $(0.000)$ & $(0.000)$ & \\
\hline
\end{tabular}

where $* * *$ indicates $\mathrm{P}$-value $<0.01$ ( $1 \%$ significance level), and $* *$ indicates $\mathrm{P}$-value $<0.05$ (5\% significance level).

\section{Source: Researcher's Compilation, 2021.}

The result shows that if the $\mathrm{p}<0.05$, it implies that a significant correlation exists between the variables. As indicated in the table above, the effect of the coronavirus pandemic is significant with procurement, transportation, forecasting/quantification of HIV test kits, client assessing, and inventory management at $\mathrm{P}$-value $(0.000)<0.05$ (5\% significance level). This shows that the explanatory variables have a significant impact on the dependent variable (effect of coronavirus pandemic).

From the result, it is observed that all variables indicate that a strong positive relationship occurs between the variables. This implies that as procurement or transportation or forecasting and quantification, client assessing, and inventory management increase, the level of the effect of coronavirus pandemic also increases. This means that all the explanatory variables are a determinant factor of the level of the coronavirus pandemic. 


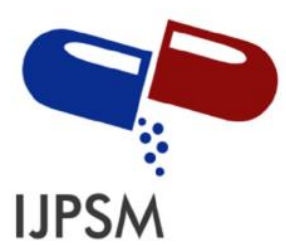

Michael Olabode Tomori et al, Int. Journal of Pharmaceutical Sciences and Medicine (IJPSM), Vol.6 Issue. 9, September- 2021, pg. 34-78

\subsection{Hypothesis Testing}

Effect of coronavirus pandemic was examined on the supply chain of HIV test kits.

3.3.1 Hypothesis testing on effect of coronavirus on the procurement of HIV test kits

Table 16 Effect of coronavirus pandemic on the procurement of HIV test kits.

\begin{tabular}{ccccc}
\hline & B & Std.Error & t & P-value \\
\hline Constant & 1.431 & 0.289 & 4.957 & $0.000 * * *$ \\
\hline Procurement & 0.697 & 0.079 & 8.797 & $0.000 * * *$ \\
\hline & \multicolumn{1}{c}{ Model Summary } & & \\
\hline Model & SS & DF & MS & \\
\hline Error & 61.544 & 1 & 61.544 & \\
\hline Adj R-square & 68.399 & 86 & 0.795 & F $(1,86)=77.382$ \\
\hline & 0.468 & R-square & 0.474 & Prob $>$ F $=0.000$ \\
\hline
\end{tabular}

where $* * *$ indicates $\mathrm{P}$-value $<0.01$, and $* *$ indicates $\mathrm{P}$-value $<0.05$.

Source: Researcher's Field Survey, 2021.

\section{Interpretation}

Model 1:

$$
\begin{gathered}
\mathrm{ECP}_{\mathrm{i}}=\mathrm{a}+\mathrm{b}_{1} \text { Procurement }_{\mathrm{i}}+\mathrm{e}_{\mathrm{i}} \\
\left.\mathrm{ECP}_{\mathrm{i}}=1.431+0.691 \text { (Procurement }_{\mathrm{i}}\right) .
\end{gathered}
$$

Table 16 reveals the regression analysis and the model summary of the effect of the coronavirus pandemic on the procurement of HIV test kits in Ondo State, Nigeria. The result of the model summary shows the adjusted $\mathrm{r}$ square which illustrates that $46.8 \%$ of the variation in procurement is explained by the explanatory variable (procurement). This implies 


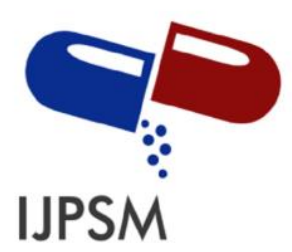

Michael Olabode Tomori et al, Int. Journal of Pharmaceutical Sciences and Medicine (IJPSM), Vol.6 Issue. 9, September- 2021, pg. 34-78

ISSN: 2519-9889

Impact Factor: 3.426

that procurement contributes to the effect of the coronavirus pandemic in a positive and significant way.

Following the result of the analysis, the coefficient value of procurement is revealed in Table 16 showing $(b=0.691)$. The coefficient of the explanatory variable shows a positive contribution to the effect of the coronavirus pandemic.

A decision rule is set based on the hypothesis set in Chapter One. The decision rule states that if the probability value is less than either 0.01 or 0.05 , reject the null hypothesis, otherwise, do not reject the null hypothesis. From the result, the p-value obtained is rejected at P-value < 0.01. The result reveals that pandemic has a significant effect on the procurement of HIV tests with $\mathrm{P}$-value $=0.000$ with the $\mathrm{F}$ statistic value of 77.382 . This implies that a significant effect is obtained from the procurement of HIV test kits among the health facilities in Ondo State, Nigeria.

3.3.2 Hypothesis testing on effect of the coronavirus pandemic on the transportation/distribution of HIV test kits to supported health facilities.

The effect of coronavirus pandemic on the transportation/distribution of HIV test kits to supported health facilities using ordinary least square regression analysis. The result of the model is conducted and explained as follows.

Table 17: Effect of the coronavirus pandemic on transportation/distribution of HIV test kits to supported health facilities

\begin{tabular}{ccccc}
\hline & B & Std.Error & t & P-value \\
\hline Constant & 1.411 & 0.364 & 3.874 & $0.000 * * *$ \\
\hline Transportation & 0.689 & 0.099 & 6.936 & $0.000 * * *$ \\
& \multicolumn{2}{c}{ Model Summary } & & \\
\hline & SS & DF & MS & \\
\hline Model & 46.614 & 1 & 46.614 & \\
\hline
\end{tabular}




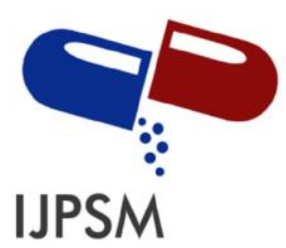

Michael Olabode Tomori et al, Int. Journal of Pharmaceutical Sciences and Medicine (IJPSM), Vol.6 Issue. 9, September- 2021, pg. 34-78

ISSN: 2519-9889

Impact Factor: 3.426

\begin{tabular}{ccccc}
\hline Error & 83.329 & 86 & 0.969 & $\mathrm{~F}(1,86)=48.108$ \\
\hline Adj R-square & 0.351 & R-square & 0.359 & Prob $>\mathrm{F}=0.000$ \\
\hline
\end{tabular}

where $* * *$ indicates $\mathrm{P}$-value $<0.01$, and $* *$ indicates $\mathrm{P}$-value $<0.05$.

Source: Researcher's Compilation, 2021.

\section{Interpretation}

\section{Model 2:}

$$
\begin{gathered}
\mathrm{ECP}_{\mathrm{i}}=\mathrm{a}+\mathrm{b}_{1} \text { Transportation }_{\mathrm{i}}+\mathrm{e}_{\mathrm{i}} \\
\mathrm{ECP}_{\mathrm{i}}=1.431+0.691\left(\text { Transportation }_{\mathrm{i}}\right) .
\end{gathered}
$$

The result of the adjusted $\mathrm{r}$ square shows that $35.1 \%$ of the explanatory variable (transportation) is being explained by the dependent variable (effect of coronavirus pandemic) with the degree of freedom of 1,86 . This shows a good fit for the pandemic and transportation or distribution of the HIV test kits among the supported health facilities in Ondo State, Nigeria.

The result of the model explains in Table 4.16 shows that transportation or the distribution of the HIV test kits is significant at a P-value $<0.01$ (1\% level of significance). This shows that the variable contributes positively to the effect of the coronavirus pandemic in Ondo State. The variable has a coefficient value of (0.689). This implies that the more increase in the distribution of HIV test kits leads to an increase in the effect of the coronavirus pandemic.

The decision rule states the null hypothesis is rejected at $\mathrm{P}$-value $<0.01$, and 0.05 respectively. This implies that Coronavirus affects the transportation and distribution of HIV test kits among the supported health facilities in Ondo State, Nigeria. 


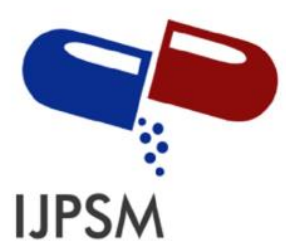

Michael Olabode Tomori et al, Int. Journal of Pharmaceutical Sciences and Medicine (IJPSM), Vol.6 Issue. 9, September- 2021, pg. 34-78

ISSN: 2519-9889

Impact Factor: 3.426

3.3.3 Hypothesis testing of effect of the pandemic on forecasting and quantification of HIV test kits

The effect of the pandemic on forecasting and quantification of HIV test kits is analyzed in the section below using OLS regression.

Table 18: Effect of the coronavirus pandemic on forecasting and quantification of HIV test kits.

\begin{tabular}{ccccc}
\hline & B & Std.Error & t & P-value \\
\hline Constant & 1.497 & 0.326 & 4.593 & $0.000 * * *$ \\
\hline Transportation & 0.686 & 0.091 & 7.530 & $0.000 * * *$ \\
\hline & \multicolumn{2}{c}{ Model Summary } & & \\
\hline Model & SS & DF & MS & \\
\hline Error & 51.629 & 1 & 51.629 & \\
\hline Adj R-square & 78.315 & 86 & 0.911 & $\mathrm{~F}(1,86)=56.695$ \\
\hline
\end{tabular}

where $* * *$ indicates $\mathrm{P}$-value $<0.01$, and $* *$ indicates $\mathrm{P}$-value $<0.05$.

Source: Researcher's Compilation, 2021.

\section{Interpretation}

Model 3:

$$
\begin{gathered}
\mathrm{ECP}_{\mathrm{i}}=\mathrm{a}+\mathrm{b}_{1} \text { Forecasting }_{\mathrm{i}}+\mathrm{e}_{\mathrm{i}} \\
\mathrm{ECP}_{\mathrm{i}}=1.431+0.691\left(\text { Forecasting }_{\mathrm{i}}\right) .
\end{gathered}
$$

An adjusted $\mathrm{r}$ square of $39.0 \%$ of the forecasting and quantification is explained in the dependent variables (ECP) while $61 \%$ of the variation is lost to an error term or variable that is not captured in the analysis. 


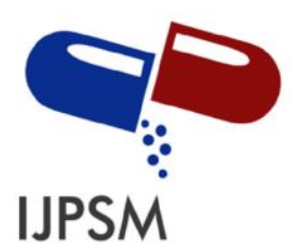

Michael Olabode Tomori et al, Int. Journal of Pharmaceutical Sciences and Medicine (IJPSM), Vol.6 Issue. 9, September- 2021, pg. 34-78

The result of the analysis in the table above, the analysis indicates that a significant positive effect of forecasting and quantifying HIV test kits are indicated in the analysis. This is as a result of the analysis displayed in Table 18 above. The coefficient of the explanatory variable is given as 0.686 with the standard error of 0.091 . This means that as forecasting and quantification of the HIV test kits increases, the effect of the coronavirus pandemic also increases. Also, a unit increase of forecast and quantification of HIV test kits will increase the effect of the coronavirus pandemic.

The null hypothesis is rejected at the P-value $<0.05$ (5\% level of significance) which implies that the pandemic affects the forecasting and quantification of HIV test kits at P-value = 0.000 which is considered to be less than 0.01 and 0.05 respectively.

\subsubsection{Hypothesis testing of effect of coronavirus pandemic on health workers in charge of HIV test kit.}

This section is analyzed using OLS regression analysis. The section investigates the effect of the coronavirus pandemic on health workers in charge of HIV test kits.

Table 19: Effect of the coronavirus pandemic on health workers in charge of HIV test kit.

\begin{tabular}{cccccc}
\hline & B & Std.Error & t & P-value \\
\hline Constant & 1.395 & 0.342 & 4.078 & $0.000 * * *$ \\
\hline Charge & 0.691 & 0.093 & 7.458 & $0.000 * * *$ \\
\hline & \multicolumn{2}{l}{ Model Summary } & & \\
\hline Model & SS & DF & MS & \\
\hline Error & 51.032 & 1 & 44.135 & \\
\hline Adj R-square & 78.911 & 86 & 0.998 & $\mathrm{~F}(1,86)=55.617$ \\
\hline & 0.386 & R-square & 0.393 & Prob $>\mathrm{F}=0.000$ \\
\hline
\end{tabular}

where $* * *$ indicates $\mathrm{P}$-value $<0.01$, and $* *$ indicates $\mathrm{P}$-value $<0.05$.

Source: Researcher's Compilation, 2021. 


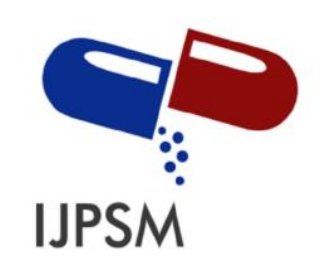

Michael Olabode Tomori et al, Int. Journal of Pharmaceutical Sciences and Medicine (IJPSM), Vol.6 Issue. 9, September- 2021, pg. 34-78

ISSN: 2519-9889

Impact Factor: 3.426

\section{Interpretation}

\section{Model 4:}

$$
\begin{gathered}
\mathrm{ECP}_{\mathrm{i}}=\mathrm{a}+\mathrm{b}_{\mathrm{i}} \text { Charging }+\mathrm{e}_{\mathrm{i}} \\
\mathrm{ECP}_{\mathrm{i}}=1.431+0.691\left(\text { Charging }_{\mathrm{i}}\right) .
\end{gathered}
$$

$38.6 \%$ of the independent variable is explained in the pandemic using the value obtained for the adjusted $\mathrm{r}$ square. The result of the analysis shows that $61.4 \%$ of the variables are not captured in the analysis or lost to an error term or random error or white noise.

A significant effect between the health workers in charge and the pandemic is analyzed and the result is obtained above. The result demonstrated that health workers in charge of HIV test kits have a positive significant effect on the pandemic. This implies that a unit increase in the health workers in charge of HIV test kits leads to an increase in pandemic with the coefficient value of 0.691 .

The decision rule was stated at p-value $<0.01$ and 0.05 respectively. From the result, there is a statistically significant effect between the pandemic and the health workers in charge of HIV test kits which implies that the null hypothesis was rejected at $\mathrm{P}$-value $=0.000$. This also shows that pandemics affect the health workers in charge of the test kits.

\subsubsection{Hypothesis testing of effect of coronavirus pandemic on client assessing HIV testing}

This section is analyzed using OLS regression analysis. The section investigates the effect of coronavirus pandemic. 


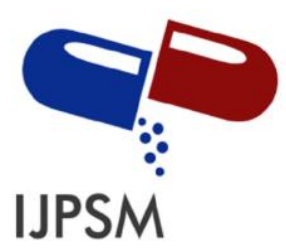

Michael Olabode Tomori et al, Int. Journal of Pharmaceutical Sciences and Medicine (IJPSM), Vol.6 Issue. 9, September- 2021, pg. 34-78

Table 20: Pandemic on clients accessing HIV testing

\begin{tabular}{|c|c|c|c|c|}
\hline & B & Std.Error & $\mathbf{t}$ & P-value \\
\hline Constant & 2.221 & 0.312 & 7.114 & $0.000 * * *$ \\
\hline \multirow[t]{3}{*}{ Client assessing } & 0.450 & 0.081 & 5.523 & $0.000 * * *$ \\
\hline & \multicolumn{3}{|c|}{ Model Summary } & \\
\hline & SS & DF & MS & \\
\hline Model & 34.020 & 1 & 34.020 & \\
\hline Error & 95.923 & 86 & 1.115 & $F(1,86)=30.501$ \\
\hline Adj R-square & 0.253 & $\mathrm{R}$-square & 0.262 & Prob $>F=0.000$ \\
\hline
\end{tabular}

\section{Interpretation}

\section{Model 5:}

$$
\begin{gathered}
\mathrm{ECP}_{\mathrm{i}}=\mathrm{a}+\mathrm{b}_{\mathrm{i}} \text { Client_Assessing }+\mathrm{e}_{\mathrm{i}} \\
\mathrm{ECP}_{\mathrm{i}}=1.431+0.691_{\mathrm{i}}(\text { Client Assessing })
\end{gathered}
$$

The total variables of explanatory variables being explained by the pandemic are $25.3 \%$. This shows that there is a significant relationship from the chi-square used on pandemic as a dependent variable. The result shows that there is a significant effect of client assessing and pandemic.

The coefficient value is given as 0.450 and the $\mathrm{P}$-value $<0.05$. This demonstrates that there is a significant positive effect between pandemic and client assessing with the p-value of 0.000 and the F statistics of the result is given as 30.501 which means that the null hypothesis is rejected at $\mathrm{P}$-value $<0.05$. 


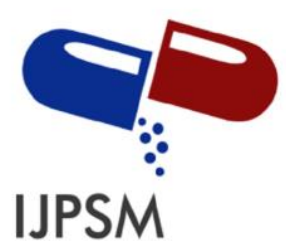

Michael Olabode Tomori et al, Int. Journal of Pharmaceutical Sciences and Medicine (IJPSM), Vol.6 Issue. 9, September- 2021, pg. 34-78

\subsubsection{Hypothesis testing of coronavirus on inventory management of HIV test kits}

The inventory management of the HIV test kits is used as an explanatory variable to determine the effect of coronavirus among the supported health facilities in Ondo State, Nigeria.

Table 20: Effect of the coronavirus pandemic on inventory management of HIV test kits.

\begin{tabular}{ccccc}
\hline & B & Std.Error & t & P-value \\
\hline Constant & 2.303 & 0.253 & 9.098 & $0.000^{* * *}$ \\
\hline Inventory & 0.537 & 0.081 & 6.651 & $0.000^{* * *}$ \\
\hline & \multicolumn{2}{c}{ Model Summary } & & \\
\hline Model & SS & DF & MS & \\
\hline Error & 44.135 & 1 & 44.135 & \\
\hline Adj R-square & 85.808 & 86 & 0.998 & $\mathrm{~F}(1,86)=44.234$ \\
\hline
\end{tabular}

where $* * *$ indicates $\mathrm{P}$-value $<0.01$, and $* *$ indicates $\mathrm{P}$-value $<0.05$.

Source: Researcher's Compilation, 2021.

\section{Interpretation}

Model 6:

$$
\begin{gathered}
\mathrm{ECP}_{\mathrm{i}}=\mathrm{a}+\mathrm{b}_{1} \text { Inventory_Management }_{\mathrm{i}}+\mathrm{e}_{\mathrm{i}} \\
\mathrm{ECP}_{\mathrm{i}}=1.431+0.691 \text { (Inventory_Mangement }{ }_{\mathrm{i}} \text { ). }
\end{gathered}
$$

Table 20 displays that $33.2 \%$ of the inventory management is being explained in the effect of the coronavirus pandemic. The remaining $66.8 \%$ were lost to error terms or variables not captured in the model. 


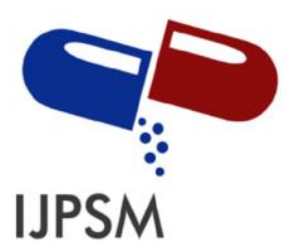

Michael Olabode Tomori et al, Int. Journal of Pharmaceutical Sciences and Medicine (IJPSM), Vol.6 Issue. 9, September- 2021, pg. 34-78

ISSN: 2519-9889

Impact Factor: 3.426

The model explains that inventory management contributes positively to the effect of the coronavirus pandemic among the health facilities in Ondo State, Nigeria with the coefficient value of 0.537 . This shows that a unit increase in inventory management, result in the effect of the coronavirus pandemic. Also, the null hypothesis is rejected at P-value $=0.000$ which implies that pandemics affect the inventory management of the HIV test in Ondo State with the $\mathrm{F}$ statistics given as 44.234 .

\subsection{Outcome of systematic review on impact of coronavirus on efforts to reach the first $95 \%$ of UNAIDS target}

\subsubsection{Positive impacts}

Despite the very fact that Coronavirus has been blamed for economic downturns, it has shifted organizational focus towards a sustainable supply chain (Amalesh et al., 2020). Other positive impacts include:

\section{Increased HIV testing:}

COVID-19 offers a chance to extend HIV testing in acute medical settings (Kelly et al., 2020, p.590-592). COVID-19 crisis could represent a chance to extend the supply of self-testing and rapid test screening in nonhospital settings including community check points, given that "traditional" testing clinics are deployed in providing care for the coronavirus pandemic.

\section{Use of digital technology:}

Hospital now acquire digital technology-based devices and software to fulfil various ongoing challenges such as Artificial Intelligence (AI) and the Internet of Things (IoTs) that provide major innovation for supply chain (Cao et al., 2020, p., 309-311). 


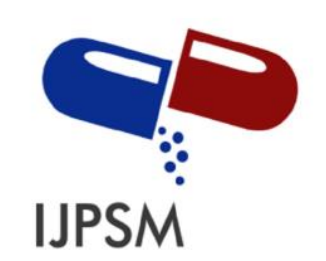

Michael Olabode Tomori et al, Int. Journal of Pharmaceutical Sciences and Medicine (IJPSM), Vol.6 Issue. 9, September- 2021, pg. 34-78

ISSN: 2519-9889

Impact Factor: 3.426

\section{Reimagination of supply chain operating model:}

Operating model that works better should be used while new model that can help prepare for future disruption can be adopted.

\section{Increased Capacity in Research and Development:}

As the world manages to contain Covid-19 outbreak, various countries and firms specialize in finding a vaccine, developing protocol to treat infected patients, adopting capabilities which enable the integrity of the processes and the quality of the products and creating a safe working environment for employees (Amalesh et al., 2020; Adepoju, 2020, p.43-52).

\subsubsection{Negative impacts}

As COVID-19 continues to spread globally, its detrimental effects on HIV/AIDS efforts worldwide have already been seen in low and middle income countries including disruptions of essential health services, such as testing, treatment, and prevention programs. It is estimated that such interruptions could result in many more additional HIV-related deaths (UNAIDS, 2020). Other negative impacts include:

\section{Disruption of HIV prevention services:}

The Global Fund (2020) in a snap shot survey conducted across facilities in Asia and Africa showed that HIV testing fell by $41 \%$ in 2020 . A large decrease in people being tested could lead on to a rise in infection rates. Disruption to HIV prevention services especially testing using HIV test kits means that people are running a higher risk of not knowing their HIV status and therefore of not accessing the treatment they need, as well as running the risk of unknowingly infecting others. Trends indicate that services are progressively resuming but it is vital to remarkably increase efforts to regain progress lost in 2020 and acquire back on track to ending HIV as an epidemic by 2030. 


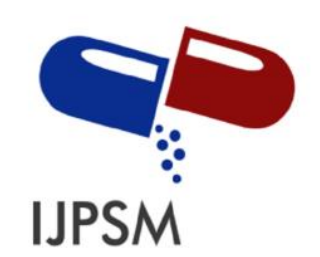

Michael Olabode Tomori et al, Int. Journal of Pharmaceutical Sciences and Medicine (IJPSM), Vol.6 Issue. 9, September- 2021, pg. 34-78

ISSN: 2519-9889

Impact Factor: 3.426

\section{Logistics constraints of distributing HIV test kits:}

Transportation services face several challenges from the supply and demand side. Most of the public transportation systems are closed in the country and this affects the distribution of HIV test kits to health facilities in urgent need of the commodity.

\section{Depletion of human resource for supply chain:}

COVID-19 has cost hundreds of thousands of human lives globally including healthcare professionals and exposed the weaknesses of national health systems worldwide (Yipeng et al., 2020, p. 277-297). Global supply chains have been disrupted due to loss of labour and raw material inputs, creating ripple effects that cross national boundaries ( $\mathrm{Yu} \&$ Aviso, 2020).

The shortage of human resources handling the HIV test kits can be seen at every level due to social distancing and other implied guidelines throughout the world. The health sector adopted the concept of the work from home for maintaining services (Vieira et al., 2020). However, this concept is not very useful because some workers are not trained or experienced for it and they lack the necessary information technology (IT) facilities to work from home.

\section{Reduced access to HIV test kits due to movement restrictions:}

In Nigeria, the lockdown was accompanied with closure of borders and travel ban across states led to a significant drop in the quantity of commodities like test kits in the health facilities.

\section{Discussion, Conclusion and Recommendations.}

\subsection{Discussion}

The study found the significant effect of the coronavirus pandemic on the supply chain of HIV test kits in Ondo State, Nigeria. The study identified six different hypotheses and are discussed accordingly. The result of the analysis devised that the supply chain on the HIV test kits is significantly affected by the pandemic. Hence, COVID-19 pandemic clearly shows the shortage of resilience in supply chains and therefore, the impact that disruptions may wear a 


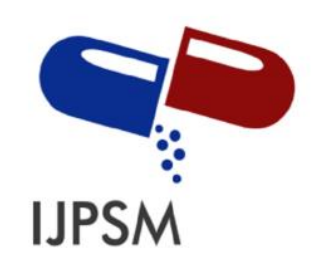

Michael Olabode Tomori et al, Int. Journal of Pharmaceutical Sciences and Medicine (IJPSM), Vol.6 Issue. 9, September- 2021, pg. 34-78

ISSN: 2519-9889

Impact Factor: 3.426

worldwide network scale as individual supply chain connections and nodes fail (Craighead et al., 2020). HIV test kit is the quick diagnostic product that is used for the testing of HIV in community through samples collected and are also known as point of care tests in HIV diagnostic. Hence, the availability of HIV test kits is very critical to the attainment of the first 95\% of UNAIDS goals towards the attainment of the 2030 targets which is that $95 \%$ of people living with HIV (PLHIV) knows their status. The result of the study shows that majority of the respondents agreed that distance from the facilities contributed to the effect of the coronavirus pandemic on the supply chain HIV test kits in Ondo State. This indicates that the variables have an impact on Supply chain of HIV test kits in Ondo State as indicated by Lagat et al. (2020) which shows the impact of the COVID 19 pandemic on HIV testing and assisted partner notification of service.

Meanwhile, the result explains the reason why Nigeria enact policies to reduce the spread of Coronavirus after the unintended disadvantages on the trend of the pandemic have been observed, particularly in the supply of HIV test kits among the CDC/UNAIDS supported health facilities. In Ondo State, the results have shown no barrier in the supply of HIV test kits among the supported health facilities, despite the fact that the result showed a significant effect of the pandemic on transportation, health workers, clients' assess and inventory management.

However, from one of the objectives and the research questions, it can be deduced from the result of the objective that the reductions in the people who access the health facilities for test and treatment of HIV can result in a poor diagnosis of HIV in the country. In addition, new people do not visit the health facilities to get tested and receive treatment due to the fear of been infected with the virus and this subsequently increases campaign of community-based HIV testing strategy to assist to improve testing coverage in the community. For instance, community testing and campaign occurred in Ondo State in the last two months where the PMTCT focal people go around the villages and communities to campaign and get people tested for HIV. This aligned with a research done by Sharma et al (2017). Furthermore, as 


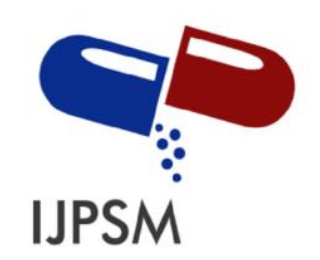

Michael Olabode Tomori et al, Int. Journal of Pharmaceutical Sciences and Medicine (IJPSM), Vol.6 Issue. 9, September- 2021, pg. 34-78

more cases of COVID-19 cases are confirmed in Nigeria, health services disruptions will likely become more serious leading to poor access of healthcare by the populace.

Globally from the literature review carried out by this study, the short-term effects of COVID-19 on health care supply chains have been severe; factory and border closures, transportation disruption, shifting demand and price increases but it is more crucial to reflect on what the long-term consequences will be and how global changes will affect the lower and middle-income countries (LMICs). This is because LMICs are in their early stages of development and thus they rely on importation of raw materials from countries outside the region notably India and China. However, crisis like pandemics tend to possess lasting impacts and it is likely that the short-term disruption of health care supply chains we are seeing will end in longer-term structural changes. This highlights the need for policy makers to address challenges to large scale and sustainable manufacturing of HIV test kits using the COVID-19 situation as a learning opportunity. While the hope is that COVID-19 will increase recognition of the importance of strong health care supply chains with commensurate investment, there will even be pressure on funders to rebuild their own shattered economies. There will be pressure to turn inward, certainly over the short term. The review has noted the very fact that disruption doesn't necessarily mean negative outcomes and that it is obligatory on all health supply chains organizations to turn this disruptive event into positive change. The COVID-19 pandemic may be a disruption of an unprecedented magnitude, which is testing the resilience of supply chains worldwide. The ability for a supply chain's operators to effectively plan, enabling a means for the supply chain to absorb, recover from, and adapt to disruptions of various lengths, impacts, and probabilities, is important to make sure the supply chain's function and success.

In the time of crisis like the pandemic, there is need to consider the new digital technologies that have potential to improve the ripple effect control in cases of epidemic outbreaks. Making innovations and data work for the supply chain resilience in crisis times, understanding and progressing the research of how these technologies can be used boost 


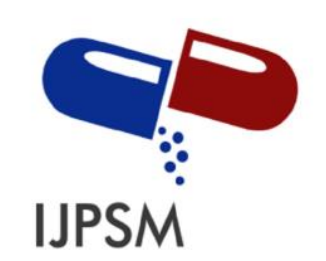

Michael Olabode Tomori et al, Int. Journal of Pharmaceutical Sciences and Medicine (IJPSM), Vol.6 Issue. 9, September- 2021, pg. 34-78

ISSN: 2519-9889

Impact Factor: 3.426

supply chains resilience, are important future research areas with a particular focus on data analytics, artificial intelligence, and machine learning (Dubey et al., 2020).

The review buttresses the need to devise and institute clear strategies on supply chain management in country and regional emergency responses, promotion of local manufacturing of HIV test kits and other health products to reduce extensive dependency on importation from international markets and increase the talent pool of supply chain management especially in Africa. The review concluded that there is need for health supply chain resilience through development of a reliable supply chain strategy for pandemics and other similar emergencies.

\subsection{Conclusion}

The study investigated the effect of the coronavirus pandemic on the supply chain of HIV tests in Ondo State, Nigeria. The hypotheses were developed for the research and tested accordingly. The findings between pandemic and the supply chain of the HIV test kits have shown a significant effect. The result reveals that all the explanatory variables are significant with P-value $<0.05$. Therefore, based on the objective set, the results shows significant effect with the pandemic in Ondo State Southwest Nigeria sub-Saharan Africa.

\subsection{Recommendation}

Based on the result and the findings obtained from the research of each model, the following are recommended which may be useful to the policymakers, government, and the stakeholder.

Since the variable obtained in the result shows a significant positive effect for the pandemic, it is recommended that national guidelines are enacted to prevent its spread. And also people should continuing assessing the health facilities on the pandemic's impact since the health 


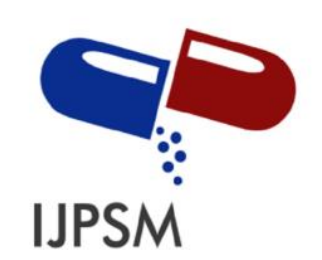

Michael Olabode Tomori et al, Int. Journal of Pharmaceutical Sciences and Medicine (IJPSM), Vol.6 Issue. 9, September- 2021, pg. 34-78

services is important to enable strategies that will decrease the service disruption and maintain the progress made on HIV pandemic so far. Other recommendations are:

- Augmentation and Utilization of Technology: Findings from recent studies suggest new supply chain technologies that will dramatically improve collaboration, visibility, agility and optimization from the beginning to the end of supply chain, comprehend complexities and support firms' ability to resist such shocks from effect of any pandemics or rare events.

- Supply chain strategies development and assessment: Most favourable supply chain planning that take into consideration the agility, resilience and sustainability are very crucial. The negative impact of the pandemic has fostered the necessity for development and implementation of health supply chain strategy. The next-generation supply chain needs a big change in outlook. Therefore, it is crucial for the health facilities to adopt an approach that is forward looking that will consist of multiple facets of the supply chain including people, processes and technology.

- Human resource supply chain strategy that includes the selection of the critical workforce that can handle the turbulence in any environment. The supply chain initiatives would require a focused Crisis Management head whose skills and responsibility are going to be to speak to all or any stake holders, consolidating requirements and setting priorities and work on risk mitigating methods of supply chain during non-crisis period. This will need scenario planning, resource optimization, and efficiency management. There is a greater need for a clinic to look beyond financial gain. Ensuring the well-being of not only their employees but also those employed even with suppliers is important if a clinic they were to evade disruptions within their supply chain.

- Adopt suitable resilience strategies that best suit each of the health facility that will prevent disruption of HIV test kits in the time of future disasters. 


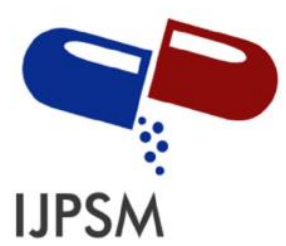

Michael Olabode Tomori et al, Int. Journal of Pharmaceutical Sciences and Medicine (IJPSM), Vol.6 Issue. 9, September- 2021, pg. 34-78

ISSN: 2519-9889

Impact Factor: 3.426

\section{REFERENCES}

[1]. Adepoju, B. (2020). Impact of COVID-19 on Supply chain operations in Nigeria. International Journal of Business and Management Invention (IJBMI) Volume 9 Issue 4 Sr. 1; PP. 43-52. Retrieved on 26 August, 2021 from: https://www. researchgate.net/ publication/341055496_Impacts_of_ COVID_19_on_supply_chain_operations_in_Nigeria.

[2]. Amalesh, S., Anirban, A., \& Sourav, B.B. (2020). Covid-19's impact on supply chain decisions: Strategic insights from NASDAQ 100 firms using Twitter data. Journal of business research-Elsevier. Received on 26 August, 2021 from https://www-sciencedirectcom.ezproxy.lib.purdue.edu/science/ article/pii/S0148296320303210.

[3]. Britta, L.J., Edinah, M., John, S., Sherrie L. K., \& Andrew, P. (2020). Potential effects of disruption to HIV programmes in sub-Saharan Africa caused by COVID-19: results from multiple $\begin{array}{llllll}\text { mathematical } & \text { models. } & \text { Retrieved } & \text { on } & \text { July } & 2020\end{array}$ from https://figshare.com/articles/Potential_effects_of disruption to_HIV_programmes in subSaharan_Africa_caused by_COVID-19 results_from_multiple mathematical_models/12279914.

[4]. Cao, Y., Li, Q., Chen, J., Guo, X., Miao, C., Yang, H., Chen, Z., Li, C., \& Li, L. (2020). Hospital emergency management plan during the COVID-19 epidemic. Academic Emergency Medicine, 27(4), 309-311.

[5]. Craighead, C.W., Ketchen, D.J. Jr., \& Darby, J.L. (2020). Pandemics and Supply Chain Management Research: Toward a Theoretical Toolbox. Decision Sciences Volume 51 Number 4.

[6]. Denscombe, M. (2007). The good research guide for small-scale research projects. 3rd ed. Open University Press. McGraw Hill.

[7]. de Mendoza, C. (2019). UNAIDS Update Global HIV Numbers. AIDS Rev.; 21:170171. [PubMed] [Google Scholar].

[8]. Duval-Couetil, N., Reed-Rhoads, T. \& Haghighi, S., 2011. The Engineering Entrepreneurship Survey: An Assessment Instrument to Examine Engineering Student Involvement in Entrepreneurship Education. The Journal of Engineering Entrepreneurship, 2(2), 35-56.

[9]. Dubey, R., Gunasekaran, A., Childe J.S., and Wamba, S.F. (2020). Empirical investigation of data analytics capability and organizational flexibility as complements to supply chain resilience. International journal of production research. Retrieved on 29 August, 2021 from: https://www.researchgate.net/deref/

[10].http\%3A\%2F\%2Fdx.doi.org\%2F10.108 0\%2F00207543.2019.1582820

[11].Dzobo, M., Chitungo, I., \& Dzinamarira, T. (2020). COVID-19: a perspective for lifting lockdown in Zimbabwe. Pan African Medical Journal; 35:13. Retrieved 27 $7^{\text {th }}$ August, 2021 from https://doi.org/10.11604/pamj.supp.2020.35.2.23059.

[12].Hair, J. F., Anderson, R. E., Tatham, R. L. \& Black, W. C., (1998). Multivariate Data Analysis. Upper Saddle River, New Jersey: Prentice-Hall.

[13].Heale, R. \& Twycross, A. (2015). Validity and Reliability in Quantitative Studies. Evidence Based Nursing, 18(3), 66-67.

[14].Kelly, S., Waters, L., \& Cevik, M. (2020). Pneumocystis pneumonia, a COVID-19 mimic, reminds us of the importance of HIV testing in COVID-19. Clin Med; 20:590-2.

[15].Lagat, H., Sharma, M., Kariithi, E., et al. (2020). Impact of the COVID-19 pandemic on HIV testing and assisted partner notification services, Western Kenya. AIDS Behav; 24: 3010-13.

[16].Liñán, F., \& Chen, Y.W. (2009). Development and Cross-Cultural Application of a Specific Instrument to Measure Entrepreneurial Intentions. Entrepreneurship Theory and Practice, 33(3), 593-617.

[17].Nunnally, J. C. (1978). Psychometric Theory. 2nd ed. New York: McGraw-Hill.

[18]. Rothan, H.A., \& Byrareddy, S.N (2020). The epidemiology and pathogenesis of coronavirus disease (COVID-19) outbreak. Journal of autoimmunity, 102433. Retrieved on $10^{\text {th }}$ July, 2021 from https://www. who.int/emergencies/diseases/novel-coronavirus-2019. 


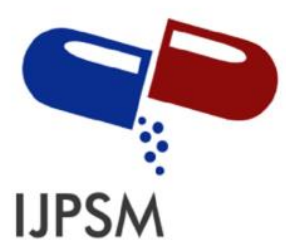

Michael Olabode Tomori et al, Int. Journal of Pharmaceutical Sciences and Medicine (IJPSM), Vol.6 Issue. 9, September- 2021, pg. 34-78

ISSN: 2519-9889

Impact Factor: 3.426

[19].Sharma, M., Barnabas, R.V. Celcum, C. (2017). Community-based strategies to strengthen men's engagement in the HIV care cascade in sub-Saharan Africa. PloS medicine, 14(4): e1002262. Doi: 10.1371/Journal.pmed.1002262.

[20].Tabachnick, G., \& Fidell, L. S. (2001). Using Multivariate Statistics. Sydney: Allan and Bacon.

[21].Tavakol, M., Mohaghehi, M. A., \& Dennick, R. (2008). Assessing the Skills of Surgical Residents Using Simulation. Journal of Surgical Education, 65(2), pp. 77-83.

[22]. The Global Fund to Fight AIDS, Tuberculosis and Malaria. (2020). The impact of COVID-19 on HIV, $\mathrm{TB}$ and malaria services and systems for health. Retrieved 24 August, 2021 from https://www.theglobalfund.org/media/10776/covid-19_2020-disruption-impact_report_en.pdf.

[23].United Nations, Department of Economic and Social Affairs, Population Division. (2019). World Population Prospects, Volume I: Comprehensive Tables. Retrieved $\quad 10^{\text {th }} \quad$ June, 2021 from https://population.un.org/wpp/Publications/Files/WPP2019_Volume-I_ComprehensiveTables.pdf.

[24].UNAIDS (2020). AIDSinfo. Retrieved on $18^{\text {th }}$ June 2021 from https://aidsinfo.unaids.org/.

[25].Van Hoek, R. (2020). Research opportunities for a more resilient post-COVID-19 supply chain closing the gap between research findings and industry practice. International Journal of Operations \& Production Management Vol. 40 No. 4, 2020 pp. 341-355. DOI 10.1108/IJOPM-03-2020-0165.

[26].Vieira, A.A., Dias, L.M., Santos, M.Y., Pereira, G.A., \& Oliveira, J.A. (2020). Supply chain data integration: A literature review. Journal of Industrial Information Integration, 100161.

[27]. World Bank. (2020). A shock like no other: The impact of Covid-19 on commodity markets. Washington, DC: World Bank.

[28].Yamane, T. (1976). Elementary Sampling Theory. Englewood Cliffs. New Jersey: $\quad$ Prentice Hall, Inc.

[29].Yipeng, L., Jong, M. L., \& Lee, C. (2020). The challenges and opportunities of a global health crisis: the management and business implications of COVID-19 from an Asian perspective. Asian Business \& Management 19, 277-297. Retrieved on $22^{\text {nd }}$ September, 2020 from https://link.springer.com/article/10.1057/s41291-020-00119-x.

[30].Yu, K.D.S., \& Aviso, K.B. (2020). Modelling the economic impact and ripple effects of disease outbreaks. Process Integration and Optimization for Sustainability, 1-4.

[31].Zhou, F., Yu, T., Du, R., Fan, G., Liu, Y., Liu, Z., Xiang, J., Wang, Y., Song, B., \& Gu, X. (2020). Clinical course and risk factors for mortality of adult inpatients with COVID-19 in Wuhan, China: a retrospective cohort study. Retrieved on $22^{\text {nd }}$ September, 2020 from https://doi.org/10.1016/S01406736 (20)30566-3. 